\title{
Regulation of benthic oxygen fluxes in permeable sediments of the coastal ocean
}

\author{
Soeren Ahmerkamp ${ }^{(D)},{ }^{1 *}$ Christian Winter, ${ }^{2}$ Knut Krämer, ${ }^{2}$ Dirk de Beer, ${ }^{1}$ Felix Janssen, ${ }^{1,3}$ \\ Jana Friedrich, ${ }^{4}$ Marcel M. M. Kuypers, ${ }^{1}$ Moritz Holtappels (iD), ${ }^{1,3}$ \\ ${ }^{1}$ Max Planck Institute for Marine Microbiology, Bremen, Germany \\ ${ }^{2}$ Marum Center for Marine Environmental Sciences, Bremen, Germany \\ ${ }^{3}$ Alfred Wegener Institute - Helmholtz Center for Polar and Marine Research, Bremerhaven, Germany \\ ${ }^{4}$ Helmholtz Centre for Materials and Coastal Research, Geesthacht, Germany
}

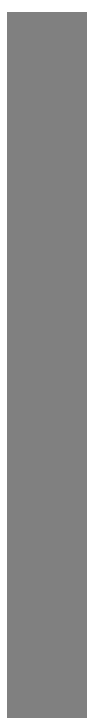

\begin{abstract}
Large areas of the oceanic shelf are composed of sandy sediments through which reactive solutes are transported via porewater advection fueling active microbial communities. The advective oxygen transport in permeable sands of the North Sea was investigated under in situ conditions using a new benthic observatory to assess the dynamic interaction of hydrodynamics, sediment morphodynamics, and oxygen penetration depth. During 16 deployments, concurrent measurement of current velocity, sediment topography, and porewater oxygen concentration were carried out. In all cases the oxyclines were found at depths of 1-6 cm, correlating with the topography of stationary and migrating bedforms (ripples). Different conditions in terms of bottom water currents and bedform migration led to fluctuating oxygen penetration depths and, hence, highly variable redox conditions in up to $2.5 \mathrm{~cm}$ thick layers beneath the surface. Volumetric oxygen consumption rates of surface sediments were measured on board in flow-through reactors. Bedform migration was found to reduce consumption rates by up to $50 \%$, presumably caused by the washout of organic carbon that is otherwise trapped in the pore space of the sediment. Based on the observations we found oxygen penetration depths to be largely controlled by oxygen consumption rates, grain size, and current velocity. These controlling variables are summarized by an adapted Damköhler number which allows for prediction of oxygen penetretion depths based on a simple scaling law. By integrating the oxygen consumption rates over the oxygen penetration depth, oxygen fluxes of $8-34 \mathrm{mmol} \mathrm{m}^{-2} \mathrm{~d}^{-1}$ were estimated.
\end{abstract}

Despite covering only 6-8\% of the ocean surface (Sverdrup et al. 1942) continental shelves contribute to approximately $25 \%$ of the global primary production and, hence, play a crucial role for the oceanic biosphere (Jahnke 2010). Since the Industrial Revolution the coastal seas are increasingly affected by nutrient input from river runoffs and atmospheric deposition leading to eutrophication and significant changes in many coastal ecosystems (Rabalais et al. 2002; Boyer et al. 2006).

The North Sea is a prominent example of an anthropogenically eutrophied shelf sea. It is encompassed by land masses and industrialized countries and, therefore, exposed to large river runoffs leading to high nutrient inputs which fuel photosynthetic carbon fixation (Gerlach 1981). As a result of the shallow water depths-mostly below $40 \mathrm{~m}-\mathrm{a}$

*Correspondence: sahmerka@mpi-bremen.de

Additional Supporting Information may be found in the online version of this article. large fraction of the fixed organic carbon reaches the sea floor (Otto et al. 1990). While the deep North Sea has been identified as a sink for atmospheric carbon dioxide, the shallow North Sea is a source of carbon dioxide which implies active benthic organic carbon remineralization in these areas (Thomas et al. 2004). In accordance to most continental shelves in temperate and high latitudes, also the North Sea sediments are mostly composed of relict silica sand (Emery 1968).

In general, sandy sediments are low in organic carbon (de Beer 2005; Janssen et al. 2005) and, as a result of the low specific surface area of sand grains, harbor fewer microbial cells compared to muddy sediments (DeFlaun and Mayer 1983; Rusch et al. 2003). These two facts led to the misconception that sandy sediments are deserts of microbial activity and that the contribution to biogeochemical fluxes is minor (Boudreau et al. 2001). However, in the last two decades it has been shown that this assumption has erroneously equated standing stocks and process rates and neglected an important 
intrinsic characteristic of sand: the permeability, i.e., the ability to allow advective fluid flow leading to intense mixing and exchange of porewaters (Thibodeaux and Boyle 1987). In the subtidal zone of continental shelves the advective porewater flow is mainly driven by the interaction between small scale bedforms (ripples) and the overlying bottom water currents (Santos et al. 2012a,b). The bedforms act as an obstacle, and following Bernoulli's principle, cause a local acceleration of the bottom water currents which generates a pressure gradient pumping organic-rich and oxygenated bottom water through the pore space of sandy sediments (Huettel et al. 1996). In contrast to diffusion controlled cohesive sediments, the transport of reactants in permeable sediments is not driven by concentration gradients, but is a function of many variables, namely current velocity, sediment permeability, and topography. These variables exhibit a large temporal and spatial variability, which complicates the assessment of porewater transport in these sediments.

It was inferred from flume experiments (Huettel et al. 1996), modelling studies (Cardenas and Wilson 2007; Janssen et al. 2012), and volumetric rate measurements (Reimers et al. 2004; Rao et al. 2007; Marchant et al. 2014) that the advective porewater flow through sandy sediments has strong implications for the biogeochemical cycling on continental shelves (Santos et al. 2012a; Huettel et al. 2014). By pumping bottom water across the sediment-water interface the benthic infauna is supplied with electron donors and acceptors. The organic matter is degraded by a diverse microbial community that lives mostly attached to the sand grains (Rusch et al. 2003; Probandt et al. 2017). Remineralization products, such as nutrients and reduced substances, are released back to the water column enhancing the benthic pelagic coupling (Huettel et al. 1996). In contrast to cohesive sediments in which diffusive transport limits oxygen penetration to a few milimeter, the advective transport in sandy sediments leads to extended oxic and suboxic zones in which microbial processes enhance benthic remineralization (de Beer et al. 2005) and denitrification (Rao et al. 2007; Gao et al. 2012; Marchant et al. 2014, 2016) and thus counteract anthropogenic eutrophication.

In nature, the above described transport and reaction processes occur under highly variable hydrodynamic and morphodynamic conditions. Strong tides are characteristic for shallow coastal waters and the mere presence of bedforms is indicative of hydrodynamic conditions generating critical shear stress and a mobile sea bed. In situ measurements that capture these dynamics are rare. Flume experiments have shown that the oxic zone moves with the migrating bedform which potentially leads to spatially and temporally variable conditions of oxia and anoxia (Precht and Huettel 2003; Precht et al. 2004). Further, bedform migration involves an additional mode of porewater exchange. Porewater is released at the stoss side of the bedforms due to erosion of sediment, while bottom water is trapped when sediment grains are deposited at the lee side (Rutherford et al. 1993; Elliott and Brooks 1997). A recent model study, which linked bedform migration to the hydrodynamic forcing found that the combined effect of erosion and deposition of sand grains leads to the separation of the sediment into an upper mobile layer and a stationary layer underneath (Ahmerkamp et al. 2015). While the mobile layer is increasingly flushed when bedform migration accelerates, the stationary layer underneath becomes isolated which may ultimately reduce benthic oxygen fluxes by up to $90 \%$.

In situ investigations of sandy sediments on continental shelves are challenging, because the transient nature of the driving hydrodynamics (waves and tides) and the mobile seabed require observations that cover the relevant spatiotemporal scales. Therefore, the effect of porewater advection on biogeochemical processes has so far been studied predominantly in flume experiments (e.g., Huettel et al. 1996) and model simulations (e.g., Cardenas and Wilson 2007), mostly under steady state conditions. It is essential to investigate the interaction of transient hydrodynamic and morphodynamics and its effect on benthic fluxes under natural conditions to validate these laboratory findings and to identify the main variables that control the porewater transport and, subsequently, the benthic fluxes in coastal waters.

We developed an automated benthic observatory for the simultaneous acquisition of current velocity measurements, topography scanning, and high resolution oxygen profiling which can be deployed from ships in shallow shelf sea environments. In combination with on board measurements of microbial oxygen consumption rates and sediment properties, we aimed to describe and quantify how the interplay of transport factors (sediment permeability, hydrodynamic, and morphodynamic forcing of porewater advection) and microbial reaction rates effect oxygen penetration and oxygen fluxes. Based on the measurements the controlling variables were identified and a simple model was constructed that allows for estimating oxygen penetration depths and oxygen fluxes in permeable sediments.

\section{Methods}

\section{Study site}

Investigations were carried out in the German Bight, which is the southeastern part of the North Sea encompassed by the Netherlands, Denmark, and Germany. The German Bight is characterized by strong hydrodynamic forcing caused by semi-diurnal tides and wind-induced surface gravity waves (Grashorn et al. 2015). The mainly westerly wind-forcing shows seasonal variabilities with highest wind speeds in spring, followed by late autumn and winter (Coelingh et al. 1996). Strong discharges from the rivers Elbe, Rhine, Ems, and Weser lead to anthropogenic nutrient enrichment fueling high primary production (Brockmann et al. 1988; Hickel et al. 


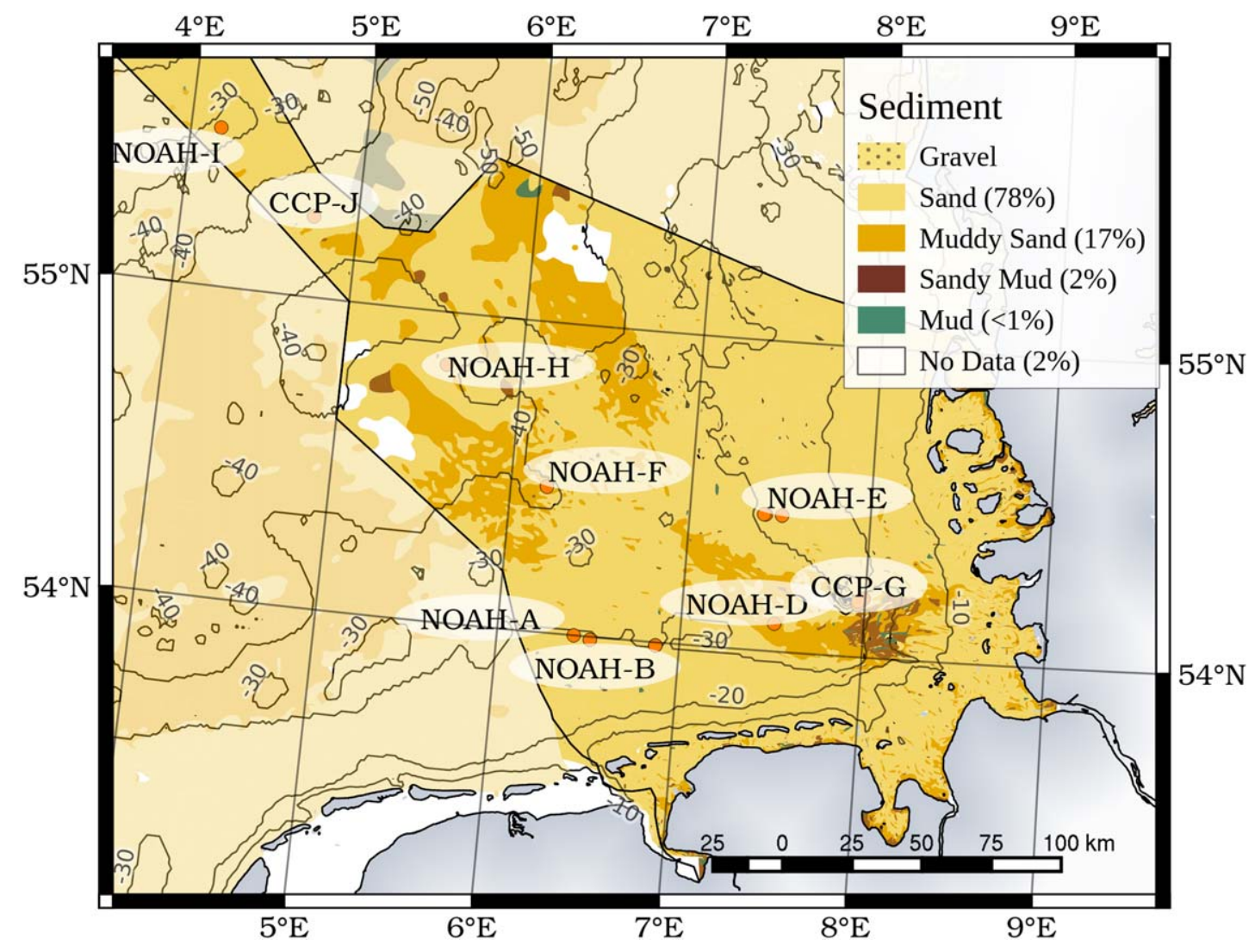

Fig. 1. The sediment distribution of the German Bight and the nine sampling areas where a total of 16 deployments of the benthic observatory were performed. The colors indicate the sediment classification after Folk et al. (1980) with the relative areal contribution in brackets. The exclusive economic zone of Germany is depicted as the bold black line, while the thin lines indicate the bathymetry with values in meters (Data provided by Geopotential Deutsche Nordsee and EMODnet).

1993; van Beusekom 2005). Shallow water depths of less than $40 \mathrm{~m}$ cause strong bentho-pelagic coupling because the retention times of aggregates in the water column are short (Simon et al. 2002). Benthic heterotrophic degradation is, therefore, driven by biannual pelagic plankton blooms triggered by light availability and increasing stratification in late spring (van Duyl and Kop 1994; Chiswell 2011).

The sea-floor is mostly covered by clastic sediments (Fig. 1) of which 95\% are composed of sand (fraction above 63 $\mu \mathrm{m})$. It has been estimated that $60 \%$ of the area is covered by sands with pemeabilites that allow for advective porewater flow at rates that may significantly affect biogeochemical process (Janssen et al. 2005). Less than 3\% are covered by cohesive sediments such as mud (fraction below $63 \mu \mathrm{m}$ ) and sandy mud. For the purpose of this study, sandy sediments are subclassified into sand (at least 90\% sand content) and muddy sand (mostly sand with 10-50\% mud) (see Fig. 1, after Folk 1980).

\section{In situ measurements}

Investigations took place during three field trips with the research vessel Heincke (He417, He432, He447) in March 2014, September 2014, and July 2015, respectively (Table 2).
In total, 16 deployments of the benthic observatory were carried out in nine areas which were chosen as representative areas for distinct sedimentary environments within the German NOAH project ("North Sea Observation and Assessment of Habitats," 2013-2019). The positions were selected based on the governing grain size distribution to cover the full range as present in the North Sea.

The measurements in subtidal regions of the German Bight require autonomous observatories which sustain strong current and wave forcing. Therefore, a quadropod with a platform area of $1.5 \mathrm{~m} \times 1.5 \mathrm{~m}$ was designed, which ensures a stable positioning and minimal movements during deployment (Supporting Information Fig. S3a). The distance between the sea floor and observatory base was adjusted to $1.5 \mathrm{~m}$. An accurate positioning of the benthic observatory toward the tidal currents was achieved by using a launcher with a remotely operated releaser allowing online reading of the instrument's heading (Herbst Environmental Science, Brakel, Germany) (Supporting Information Fig. S3b). The observatory was released when facing the main flow direction. Retrieval was achieved by means of a popup buoy (875PUB, Teledyne Benthos). 
Bottom water oxygen was measured using an optode (Aandera 4330, Aanderaa Data Instruments, Bergen, Norway) mounted on top of the benthic observatory. Bottom water currents were measured using an acoustic Doppler velocimeter (ADV, Vector, Nortek) and an acoustic Doppler current profiler (ADCP, $1200 \mathrm{kHz}$, Teledyne, RD Instruments). Additional instruments for oxygen profiling and topography mapping (see below) were attached to a motor driven sledge mounted underneath the instrument platform of the benthic observatory and connected to a PC/104 board (EM104PI6023, intel) via a RS-485 bus and Firewire 1394.

\section{Oxygen profiling}

Oxygen profiles in the sediment were measured using optodes with a tip diameter of $430 \mu \mathrm{m}$ (Bare Fiber Oxygen Minisensor, High Speed, Pyroscience). Four optodes were mounted next to each other at $5 \mathrm{~cm}$ distances and attached to a linear drive that allows for an accurate vertical positioning (Supporting Information Fig. S3c). The linear drive itself was attached to the sledge for horizontal positioning. The optode bare fibers were glued into needles of $15 \mathrm{~cm}$ length and $1 \mathrm{~mm}$ diameter using epoxy resin so that the dead volume in the needle was filled and the tip of the needle protrudes approximately $0.5 \mathrm{~mm}$ beyond the sensor tip. This minimized abrasion of the oxygen sensitive fluorescent coating and increased stability during sediment penetration.

Prior to the field campaign the optodes were tested in coarse grained sediments in the laboratory. The optodes were able to resolve oxygen gradients during at least 40 consecutive profiles before the signal intensity fell below its critical value. In the field, optodes were exchanged usually for every station so that the average number of profiles for a single optode was 18. Inserting the optodes in deoxygenated water revealed a response time $\left(t_{90}\right)$ of $0.7 \mathrm{~s}(+/-0.2 \mathrm{~s})$ which agreed with the response time of less than $0.8 \mathrm{~s}$ as specified by the manufacturer. Profiling under in situ conditions was performed in 0.5$2 \mathrm{~mm}$ discrete steps, each step lasting for $2.5 \mathrm{~s}$ during which 3-4 subsequent measurements were recorded. This allowed to observe the convergence to ambient oxygen concentrations at each step. While the first measurement was typically elevated by $5-10 \%$ the subsequent measurements showed no significant difference in oxygen concentrations. The profiling depth was usually $10 \mathrm{~cm}$ and the time for the simultaneous profiling of four optodes took approximately $8 \mathrm{~min}$. After each profiling, the sledge was moved horizontally by $20 \mathrm{~cm}$ before the next simultaneous profiling of four optodes started. The sledge was repositioned 3 times so that in total 12 profiles were taken at $5 \mathrm{~cm}$ spacing, covering a total horizontal distance of $60 \mathrm{~cm}$. The complete profiling took $30 \mathrm{~min}$ and was repeated at $1 \mathrm{~h}$ intervals. The optodes were calibrated at every single profile using in situ measurements of bottom water oxygen and zero oxygen reading in the anoxic part of the sediment.

\section{Topography mapping}

The measurement of the small scale topography was based on the underwater laser scanning instrument described by Cook et al. (2007). It consisted of a laser (658 nm, 40 $\mathrm{mW}$ streamline laser, sela) with a line optic (i.e., a cylindrical lens) projecting from above $\left(90^{\circ}\right.$ angle) a $30 \mathrm{~cm}$ line onto the sea bed and a camera (Guppy Pro, AVT) that recorded the deflection of the line. The laser line was oriented perpendicular to the direction of the sledge movement. The camera was adjusted in a $45^{\circ}$ angle to the laser sheet and in the direction of the sledge movement. Laser and camera were mounted to the sledge which was moved in longitudinal direction by a linear drive. For each surface scan the speed was kept constant at a velocity of $2.5 \mathrm{~mm} \mathrm{~s}^{-1}$ and 160 pictures were recorded at intervals of $2 \mathrm{~s}$. The topography was reconstructed from the deflection of the laser line along spatial gradients. For better visualization a shaded relief of the topography was produced using the 3D-rendering opensource software Blender (version 2.72) (similar to visualizations by Glud et al. 2003).

After deployments the laser was replaced by a chess board pattern and the instruments were immersed into North Sea water to take calibration pictures. Based on these, raw pictures from the bedform recordings were rectified. Afterwards, each picture was decomposed into pixel slices perpendicular to the laser line. In each pixel slice the intensity maximum was determined at sub-pixel resolution by determination of the center of a five-point Gaussian fit around the maximum intensity. The final image reconstruction was post processed using an outlier detection and median filter. The vertical resolution is mainly limited due to the error in rectification and peak locking in cases of overexposure. At strong light conditions the accuracy of peak determination was lowest but still within 5 px leading to a maximum error of $1.5 \mathrm{~mm}$. The accuracy of the rectification and calibration procedure was validated in flume experiments prior to the in situ investigations. The final topography reconstruction encompasses an area of $0.8 \mathrm{~m} \times 0.3 \mathrm{~m}$ with a grid resolution of $5 \mathrm{~mm}$ and $2 \mathrm{~mm}$ in longitudinal and transversal direction, respectively. During deployments, laser surface scans were performed in intervals of 10-50 min.

Residual bedload transport was estimated by separating the temporal gradient of the surface topography into positive components, i.e., sediment deposition, and negative components, i.e., sediment erosion. The absolute values of both components were averaged to calculate the residual bedload flux. As this method is susceptible to noise the threshold for significant bedload transport was estimated to be $1 \times 10^{-3} \mathrm{~m}^{3} \mathrm{~m}^{-2} \mathrm{~d}^{-1}$.

Further, from the bedform reconstructions the characteristic bedform height $\delta$ was determined using the standard deviation $\sigma$ of the local height displacement $\eta_{\mathrm{xy}}$, i.e., $\delta=2 \sqrt{2} \sigma_{\eta}$ (Stonedahl et al. 2010). Bedform wavelength $\lambda$ and migration celerity $c_{\mathrm{ph}}$ were determined by the auto-correlation and crosscorrelation function, respectively (Ayoub et al. 2014). For 
comparison and for visualization, an edge detection algorithm was implemented as described by Traykovski et al. (2007). A top-hat filter was used to extract the bedform features from the reconstructions (Krämer and Winter 2016). The results were fairly similar, even though the edge detection was more susceptible to noise.

\section{Bottom water currents}

To determine the effects of hydrodynamics on the bedforms, we calculated the shear stress and wave properties from current velocity profiles recorded with an ADCP at $1 \mathrm{~Hz}$. Bedform migration is initialized when the overlying fluid exceeds a critical velocity and sediment starts to move. The force acting on the sediment surface is given by the bed shear stress which is estimated by fitting the velocity profile of the ADCP to the log law:

$$
U(z)=\frac{U_{*}}{\kappa} \cdot \ln \left(\frac{z}{z_{0}}\right)
$$

where $z$ is the depth, and $\kappa=0.41$ the Karman constant. The free variables were the roughness length $\left(z_{0}\right)$ and the shear velocity $\left(U_{*}=\sqrt{\frac{\tau}{\rho}}\right)$ with $\tau$ the bed shear stress and $\rho$ the water density. As reference for the theoretical initialization of sediment movement a critical shear stress is determined based on the non-dimensional grain size $D_{*}=d_{\mathrm{g}}\left[\frac{g(s-1)}{\rho v^{2}}\right]^{1 / 3}$ after Soulsby et al. (1997):

$$
\frac{\tau_{\mathrm{cr}}}{(s-1) g d_{\mathrm{g}}}=\frac{0.3}{1+1.2 D_{*}}+0.55\left(1-e^{-0.20 D_{*}}\right)
$$

where $g$ is acceleration due to gravity, $v$ is the kinematic viscosity, $s=\frac{\rho_{\mathrm{s}}}{\rho}$ the density ratio between silica sediment $\left(\rho_{\mathrm{s}}\right)$ and water $(\rho)$, and $d_{\mathrm{g}}$ the median grain size.

In order to determine the influence of waves, the wave orbital velocity is computed. The wave direction is determined by rotating the coordinate system until variance is maximized. Subsequently, after inspection of the spectrum, the signal is high pass filtered using a $2^{\text {nd }}$ order Butterworth filter with a cutoff frequency of $0.02 \mathrm{~Hz}$ to separate the tidal component $U$ from the fluctuating components $\left(u^{\prime}\right.$ and $\left.v^{\prime}\right)$, of which the variance can be used to calculate the wave orbital velocity (Wiberg and Sherwood 2008):

$$
U_{\text {orb }}=\sqrt{2\left(\operatorname{Var}\left(u^{\prime}\right)+\operatorname{Var}\left(v^{\prime}\right)\right)}
$$

\section{Ex situ measurements}

\section{Flow through reactors}

Volumetric oxygen consumption rates of surface sediments were measured in acrylic flow through reactors (FTR) which have the advantage that the reaction rate can be measured at high accuracy at realistic porewater flow velocities (Rao et al. 2007). At each station, sediments were sampled using a box corer (Oktopus, Standard Box Corer 2500) with a base area of $0.50 \mathrm{~m} \times 0.50 \mathrm{~m}$. The upper $2 \mathrm{~cm}$ of sediment were collected and homogenized. Large shell debris was removed using a $1 \mathrm{~mm}$ sieve to ensure a homogeneous distribution of sediment and prevent preferential porewater pathways in the FTRs. Bottom water was collected at 1-2 m above the sea floor by a rosette water sampler and kept in darkened 5 L Duran bottles (Schott) which were continuously mixed using a magnet stirrer while air was injected to insure air saturated oxygen concentrations. The FTRs were carefully filled with the homogenized sediment while immersed in water to avoid any gas inclusions. Using peristaltic pumps (Reglo digital MS-4/6, ISMATEC) the bottom water was pumped from bottom to top through the FTRs. The inner diameter of the FTRs was $10 \mathrm{~cm}$ while the length was $L_{\mathrm{c}}=20 \mathrm{~cm}$. Radial grooves in the lids of the FTRs ensured a homogeneous percolation. Sediment discharge into the tubing was avoided by covering the grooves with a plankton net (80 $\mu \mathrm{m}$ mesh). The FTRs were wrapped in foil to exclude light penetration and primary production. Oxygen concentrations were measured with optode flow-through cells (OXFTC, Pyroscience) attached to inlet $\left(C_{\mathrm{in}}\right)$ and outlet $\left(C_{\text {out }}\right)$. By using the retention time $r_{\mathrm{t}}=L_{\mathrm{c}} / u$ with $u$ as the bulk porewater velocity, the volumetric oxygen consumption rate can be calculated:

$$
R=\frac{\left(C_{\text {out }}-C_{\text {in }}\right)}{r_{\mathrm{t}}}
$$

At all stations two replicate FTRs were incubated for $12 \mathrm{~h}$ and the average rate was calculated from the temporal average of both replicates. Experiments were performed on board in a cold room at in situ temperatures (see Table 2) and started within 1-4 $\mathrm{h}$ after retrieving sediments and bottom water.

As a proxy for the homogeneity of the porewater flow, breakthrough curves of a conservative solute were determined following Rao et al. (2007). After finishing the respiration experiments, sodium bromide was added to the reservoir to a final concentration of $5 \mathrm{mmol} \mathrm{L}^{-1}$. At the outlet, conductivity, as a proxy of the sodium bromide concentration, was measured at $5 \mathrm{~s}$ intervals. In all experiments, the maximum smearing induced by the dispersion of porewater flow was well below $50 \%$ of the core length (see Support Information SI2), which means that the retention time of the slowest porewater parcel is prolonged by a factor of 1.5. The experimental settings ensured that the oxygen concentration at the outflow remained well above zero also for porewaters that were retained above average to prevent biases in the oxygen consumption measurements. Depending on the reaction rate this was achieved by adjusting the porewater velocity to 3.6$18 \mathrm{~cm} \mathrm{~h}^{-1}$ which is in the range of previously reported porewater advection (6-53 $\mathrm{cm} \mathrm{h}^{-1}$ ) (Reimers et al. 2004).

\section{Sediment characteristics}

Sediment cores $(\varnothing 10 \mathrm{~cm})$ were retrieved using a multicorer (Oktopus, MC-8/100). Sediment layers of $0.5-1 \mathrm{~cm}$ where homogenized and frozen at $-20^{\circ} \mathrm{C}$ on board. For carbon analysis the sediment samples were dried and ground. 
In an element analyzer (CE instruments) the total carbon content was determined in a subsample. The inorganic carbon was determined coulometrically (UIC Coulometrics, CM $5012 \mathrm{CO}_{2}$ Coulometer) in the gas phase after acidification of the sample. From the difference between total carbon content and inorganic carbon the organic carbon was calculated as weight percentage.

Grain size distributions were measured using a laser diffraction particle size analyzer (Beckman Coulter, LS 200) for 92 size classes ranging from $0.4 \mu \mathrm{m}$ to $2000 \mu \mathrm{m}$. Prior to measurements the samples were treated with hydrogen peroxide to remove organic matter. Based on the median of the grain size distribution $\left(d_{\mathrm{g}}\right)$ the permeability was estimated following the empirical relation by Gangi et al. (1985):

$$
k=\operatorname{Dar} \times 735 \times 10^{6} \times d_{\mathrm{g}}^{2}
$$

where $k$ is the permeability and Dar is the conversion factor for unit Darcy into $m^{2}\left(=9.869 \times 10^{-13}\right)$.

During FS Heincke cruise He432 ammonium profiles were measured. Sediment cores with an inner diameter of $10 \mathrm{~cm}$ were immediately transferred to a cool room which was adjusted to in situ temperature. Sediment porewater has been extracted from the core in $1 \mathrm{~cm}$ depth resolution using Rhizons (Seeberg-Elverfeldt et al. 2005). The extracted porewater was frozen immediately and stored until analysis in the institute's laboratory. Ammonium was determined fluorometrically using the OPA G327 method following Kérouel and Aminot (1997) on a continuous flow auto-analyser (AA3 SEAL Analytical).

\section{Oxygen flux estimations}

Under stationary conditions the benthic oxygen flux can be determined by integrating the volumetric oxygen consumption rates $R$ over the oxygen penetration depth:

$$
F_{\downarrow \mathrm{O}_{2}}=\delta R \theta
$$

where $\theta$ is the porosity. Because of the transient hydrodynamics and morphodynamics the spatial and temporal average of the penetration depth was calculated for each station and applied in Eq. 6. Here, the spatial average refers to the $60 \mathrm{~cm}$ transect along which oxygen distributions were determined based on 12 profiles, while the temporal average refers to the consecutive profiling over a tidal cycle (see above for details).

This study focuses on permeable sediments. Nevertheless, some stations turned out to be impermeable to flow as they could not be percolated in the FTRs. Therefore, the transport processes are governed by diffusion. For those stations oxygen consumption rates were estimated from in situ oxygen profiles by inversely solving the stationary diffusion-reaction equation using the Tikhonov regularization technique (Berg et al. 1998; Wang et al. 2008; Lettmann et al. 2012). Since bioturbation and bioirrigation could not be estimated in the in situ measurements, we assumed a simplified diffusive transport in cohesive sediments:

$$
-D_{\mathrm{p}} \cdot \frac{\partial^{2} C}{\partial z^{2}}=-R
$$

where $z$ is the depth, $R$ the respiration rate, $D_{\mathrm{p}}$ the diffusion coefficient corrected for tortuosity and temperature.

\section{Characteristic variables of porewater flow}

The advective transport through permeable sediments complicates the modelling of solute fluxes as compared to diffusive sediments, because many variables such as current velocity, bedform geometry, and permeability have to be considered. It is useful to establish characteristic variables that allow for a better description of the system. Following Darcy's law the porewater flow is a function of the pressure gradient in the sediment, the permeability $k$, the porosity $\theta$, and the kinematic viscosity of the fluid $v$. A nondimensional characteristic pressure difference of $\Delta p=0.1$ along the bedform was found for bedform dimensions that apply also for this study (Ahmerkamp et al. 2015). In dimensions, $\Delta p$ scales with the square of the bottom water velocity $U$ and can be used to define a characteristic porewater velocity. The full derivation can be found in Ahmerkamp et al. (2015):

$$
U_{\mathrm{p}}=2 \frac{k}{\theta} \frac{U^{2}}{v} \frac{\Delta p}{\lambda}
$$

$U_{\mathrm{p}}$ can be seen as the maximum pore water velocity induced by the characteristic pressure along half the bedform length $0.5 \lambda$. The characteristic porewater velocity is a useful variable to better describe the relative strength of bedform migration. The ratio of bedform migration to pressure driven advective porewater flow is given by:

$$
U_{\mathrm{r}}=\frac{c_{\mathrm{ph}}}{U_{\mathrm{p}}}
$$

Furthermore, the characteristic porewater velocity can be related to the oxygen consumption rate in the sediment to derive the non-dimensional Damköhler number:

$$
D a_{\lambda}=\frac{\tau_{\mathrm{t}}}{\tau_{\mathrm{r}}}
$$

which describes the relative timescales of oxygen reaction $\tau_{\mathrm{r}}=$ $C R^{-1}$ to oxygen transport $\tau_{\mathrm{r}}=\lambda U_{\mathrm{p}}^{-1}$. When transport rates dominate $(\mathrm{Da} \ll 1)$, the reactive solute gets transported deeply into the bedform. On the other hand, high oxygen consumption rates $(\mathrm{Da} \gg 1$ ) lead to an almost complete consumption in the vicinity of the sediment surface.

\section{Modelling of oxygen penetration depth and oxygen fluxes}

Despite the inherent complexity of the two-dimensional advective porewater transport it was shown for stationary 
Table 1. List of symbols.

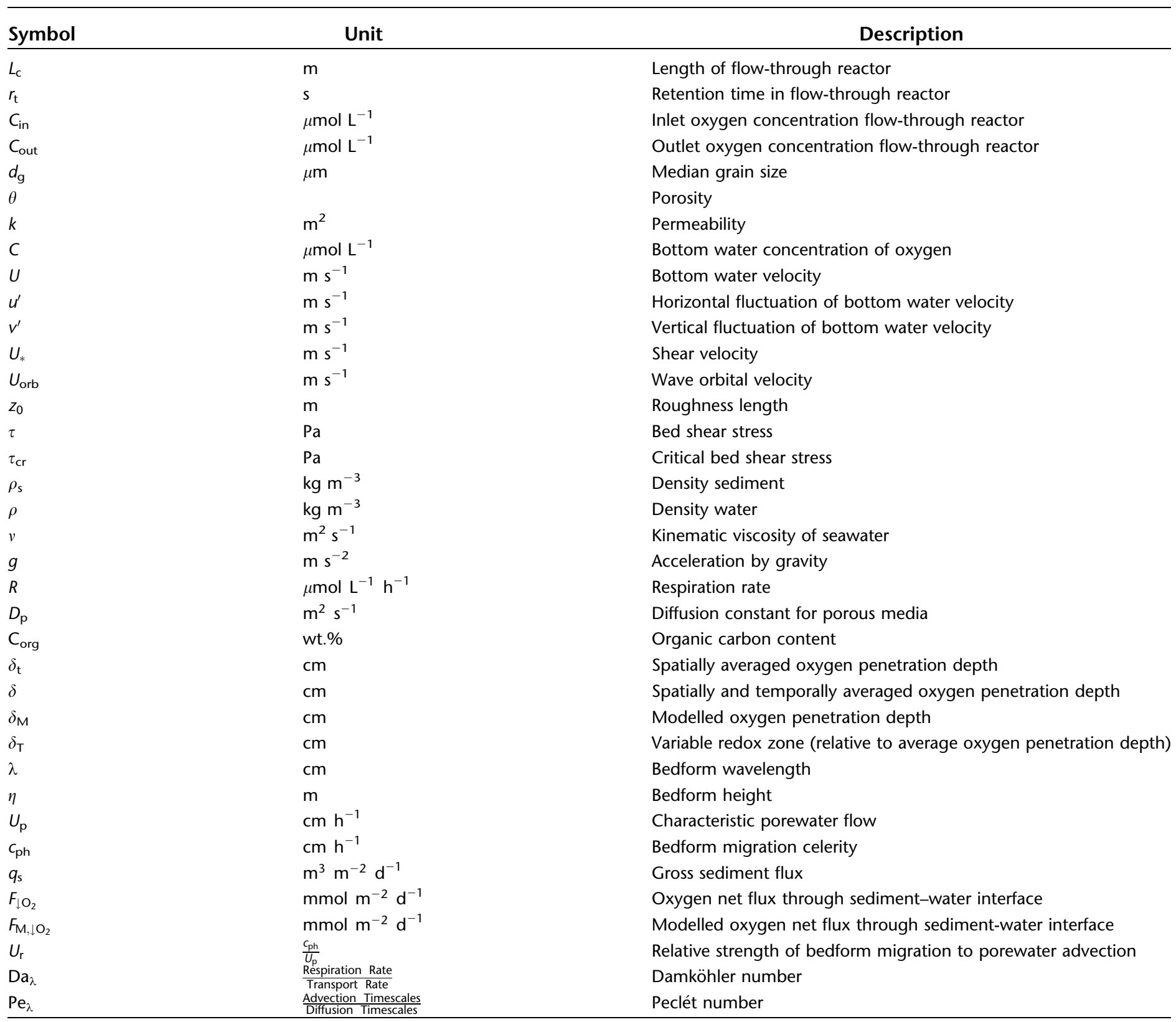

bedforms, that the spatially averaged oxygen penetration depth is proportional to the natural logarithm of the inverse Damköhler number (Elliott and Brooks 1997; Ahmerkamp et al. 2015):

$$
\delta_{\mathrm{M}}=\frac{\lambda}{2 \pi} \cdot \ln \left(0.42 \pi^{2} \cdot D a_{\lambda}^{-1}+1\right)
$$

From the modeled penetration depth $\left(\delta_{\mathrm{M}}\right)$ the flux can be calculated by integrating the respiration rate (analogous to Eq. 6):

$$
F_{\mathrm{M}, \downarrow \mathrm{O}_{2}}=\delta_{\mathrm{M}} \theta R
$$

All variables and respective units are summarized in Table 1.

\section{Results}

\section{Hydrodynamics and morphodynamics}

Bedform geometry, bedform migration, oxygen penetration depths, and corresponding hydrodynamic parameters are reported in Tables 2, 3 for the 16 different stations. Applying the sediment classification (see Methods section), muddy sand was found at 4 stations of which 2 stations exhibit bedforms, while sand was found at 12 stations of which 11 stations exhibit bedforms. Bedform length for sands ranged from $0.11 \mathrm{~m}$ to $0.29 \mathrm{~m}$ and correlated with sediment grain size (Supporting Information Fig. S2a). The ratio of bedform height and length stayed constant at a ratio of 
Table 2. Water column properties and sediment classification for the varying stations.

\begin{tabular}{|c|c|c|c|c|c|c|c|c|}
\hline Station & GPS & Month & $\begin{array}{l}\text { Depth } \\
\text { m }\end{array}$ & $\begin{array}{c}\text { Velocity U } \\
\mathrm{m} \mathrm{s}^{-1}\end{array}$ & $\begin{array}{l}\text { Oxygen C } \\
\mu \mathrm{mol} \mathrm{L}^{-1}\end{array}$ & $\begin{array}{c}\text { Water } \\
\text { temperature } \\
\text { C }\end{array}$ & $\begin{array}{c}\text { Sediment } \\
\text { classification }\end{array}$ & Identifier \\
\hline${ }^{447} \mathrm{NOAH}-\mathrm{D}$ & 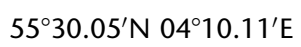 & July & 32 & 15 & 282 & 13 & Muddy Sand & \\
\hline${ }^{447} \mathrm{NOAH}-\mathrm{F}$ & $54^{\circ} 26.24^{\prime} \mathrm{N} 07^{\circ} 25.35^{\prime} \mathrm{E}$ & July & 36 & 10 & 282 & 12 & Muddy Sand & \\
\hline${ }^{432}$ CCP-J & $55^{\circ} 15.51^{\prime} \mathrm{N} 04^{\circ} 44.97^{\prime} \mathrm{E}$ & September & 38 & 5 & 255 & 10 & Muddy Sand & \\
\hline${ }^{432} \mathrm{NOAH}-\mathrm{H}$ & 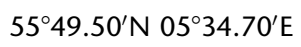 & September & 39 & 5 & 253 & 16 & Muddy Sand & \\
\hline${ }^{432} \mathrm{NOAH}-\mathrm{I}$ & 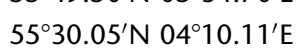 & September & 27 & 7 & 256 & 15 & Sand & \\
\hline${ }^{432} \mathrm{NOAH}-\mathrm{E}$ & $55^{\circ} 26.24^{\prime} \mathrm{N} 07^{\circ} 25.35^{\prime} \mathrm{E}$ & September & 24 & 10 & 246 & 18 & Sand & $\diamond$ \\
\hline${ }^{447} \mathrm{NOAH}-\mathrm{B}$ & 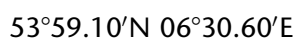 & July & 25 & 13 & 275 & 13 & Sand & 4 \\
\hline${ }^{447} \mathrm{NOAH}-\mathrm{A}$ & 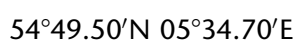 & July & 28 & 15 & 267 & 13 & Sand & $\triangleright$ \\
\hline${ }^{417} \mathrm{NOAH}-\mathrm{B}$ & 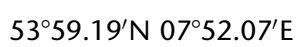 & March & 29 & 17 & 318 & 7 & Sand & + \\
\hline${ }^{447}$ CCP-G.I & $54^{\circ} 10.39^{\prime} \mathrm{N} 07^{\circ} 57.52^{\prime} \mathrm{E}$ & July & 22 & 17 & 266 & 13 & Sand & $\Delta$ \\
\hline${ }^{447} \mathrm{NOAH}-\mathrm{E}$ & $53^{\circ} 59.23^{\prime} \mathrm{N} 06^{\circ} 52.23^{\prime} \mathrm{E}$ & July & 25 & 10 & 276 & 12 & Sand & $\nabla$ \\
\hline${ }^{432}$ CCP-G.I & $54^{\circ} 10.39^{\prime} \mathrm{N} 07^{\circ} 57.52^{\prime} \mathrm{E}$ & September & 20 & 15 & 235 & 22 & Sand & $\bullet$ \\
\hline${ }^{432} \mathrm{NOAH}-\mathrm{B}$ & $53^{\circ} 59.23^{\prime} \mathrm{N} 06^{\circ} 52.23^{\prime} \mathrm{E}$ & September & 24 & 19 & 244 & 18 & Sand & $\mathbf{\square}$ \\
\hline${ }^{417}$ CCP-G.I & $54^{\circ} 10.11^{\prime} \mathrm{N} 07^{\circ} 57.31^{\prime} \mathrm{E}$ & March & 19 & 21 & 314 & 6 & Sand & - \\
\hline${ }^{417}$ CCP-G.II & $54^{\circ} 10.13^{\prime} \mathrm{N} 07^{\circ} 59.49^{\prime} \mathrm{E}$ & March & 20 & 22 & 313 & 6 & Sand & \\
\hline${ }^{417} \mathrm{NOAH}-\mathrm{E}$ & $54^{\circ} 26.25^{\prime} \mathrm{N} 07^{\circ} 24.57^{\prime} \mathrm{E}$ & March & 25 & 16 & 303 & 7 & Sand & * \\
\hline
\end{tabular}

1 : 9 (Supporting Information Fig. S2b). The shape of the bedforms was asymmetric and oriented along the main tidal flow with a gentle stoss side and a steep lee side. In conjunction, this indicates that the bedforms were largely generated by uni-directional flow (Dey 2014).

At all stations, the average bottom current velocities followed the trend of the semi-diurnal tidal cycle with velocities ranging from $7 \mathrm{~cm} \mathrm{~s}^{-1}$ to $22 \mathrm{~cm} \mathrm{~s}^{-1}$ (Fig. 2; Table 2). The tidal amplitude was similar for all stations with slight variations at spring and neap tide. Waves were present during all deployments, but the near bed wave motion did not exceed $8 \mathrm{~cm} \mathrm{~s}^{-1}$. Most of the time the oscillating near bed wave motion ranged in between $2 \mathrm{~cm} \mathrm{~s}^{-1}$ and $5 \mathrm{~cm} \mathrm{~s}^{-1}$ and did not result in oscillatory flow reversal. The bedform geometry did not correlate with the magnitude of the current velocity nor with near bed wave motions.

Sediment transport was observed at all stations that exhibit bedforms and sandy sediments. The tidal averages of residual bedload transport was between $0.27 \times 10^{-2}$ and $10 \times 10^{-2} \mathrm{~m}^{3} \mathrm{~m}^{-2} \mathrm{~d}^{-1}$ (Table 3). At 7 stations the bedload transport resulted in bedform migration of $0.7-6.5 \mathrm{~cm} \mathrm{~h}^{-1}$ (Fig. 2; Table 3). Along the tidal cycle, three different states of migration dynamics were identified: (1) no bedform migration (Fig. 2a), (2) bedform migration only during tidal peak flow (Fig. 2b), and (3) variable but continuous bedform migration (Fig. 2c,d). For the latter two states, the temporal behavior of bedform migration correlated with bottom water velocities and the exerted shear stress. As soon as the shear stress exceeded its critical value bedforms started to migrate and accelerated towards the tidal peak
(Fig. 2b-d). After reaching the peak values, the bedforms decelerated and either stopped (Fig. 2b) or continued migrating at low celerities (speed of bedform migration) (Fig. 2c,d).

Stations with muddy and mostly impermeable sand were typically located in deeper waters $(>30 \mathrm{~m}$ ) and usually exhibit no bedforms (compare Fig. 5a). One exception was ${ }^{447}$ NOAH-D (Supporting Information Fig. S4a) which had the largest bedforms of all stations in terms of length and height. On ${ }^{447}$ NOAH-F (Supporting Information Fig. S4b) topographies were visible but the cross-correlation analysis revealed that the bedforms were randomly distributed, as multiple peaks occurred. This indicates a strong contribution of biogenic structures (Ziebis et al. 1996; Cook et al. 2007).

\section{Volumetric oxygen consumption rates and organic carbon content}

Volumetric oxygen consumption rates in sandy sediments as determined in flow-through reactors varied over one order of magnitude in between $15 \mu \mathrm{mol} \mathrm{L}{ }^{-1} \mathrm{~h}^{-1}$ and $144 \mu \mathrm{mol}$ $\mathrm{L}^{-1} \mathrm{~h}^{-1}$ (Table 3 ). Replicate measurements at each station, with similar and different porewater velocities, led to variabilities in oxygen consumption rates of less than $32 \%$. Oxygen consumption rates differed significantly between stations with and without bedform migration (Fig. 3). At stations with bedform migration, oxygen consumption rates of

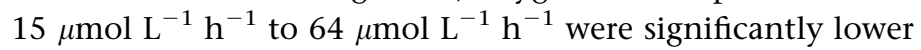
compared to stations with stationary bedforms, where oxygen consumption rates varied between $71 \mu \mathrm{mol} \mathrm{L}{ }^{-1} \mathrm{~h}^{-1}$ and $144 \mu \mathrm{mol} \mathrm{L}^{-1} \mathrm{~h}^{-1}$. 


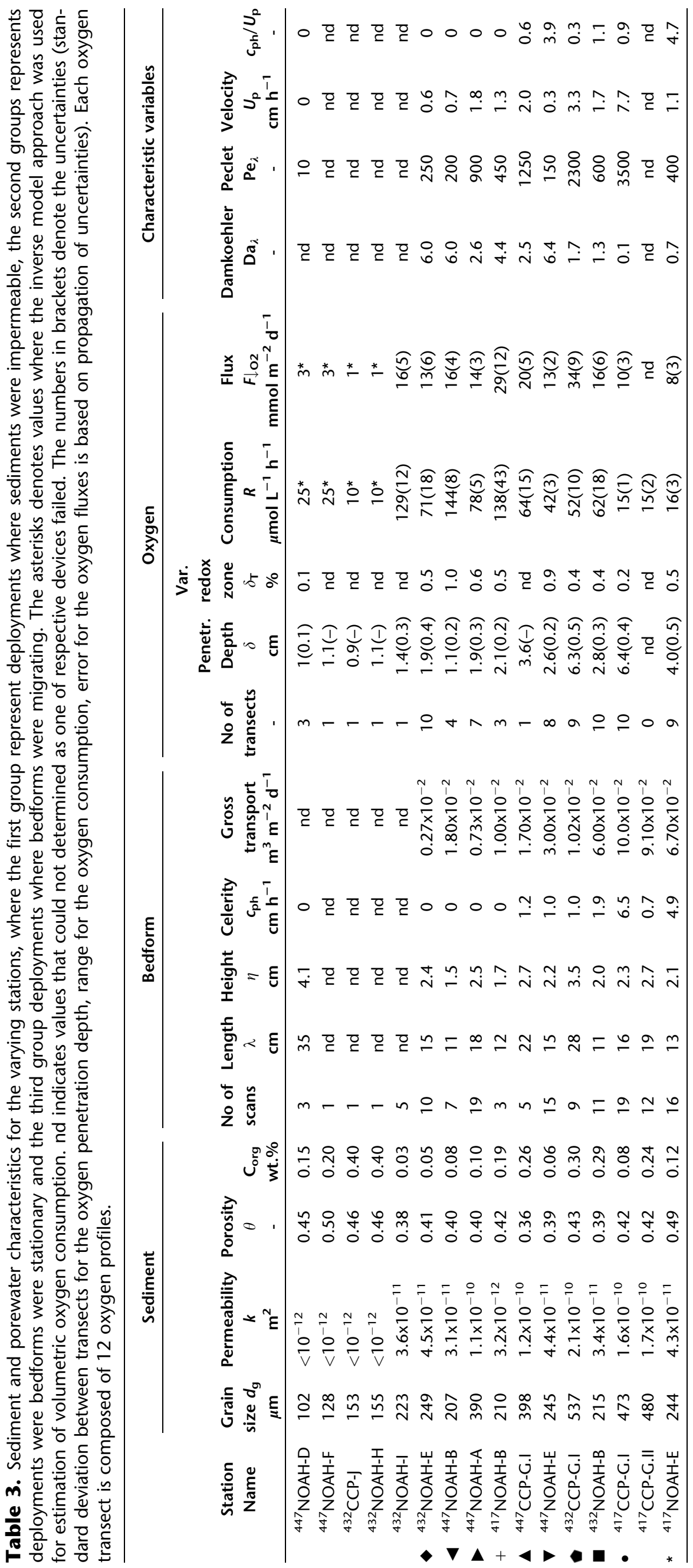



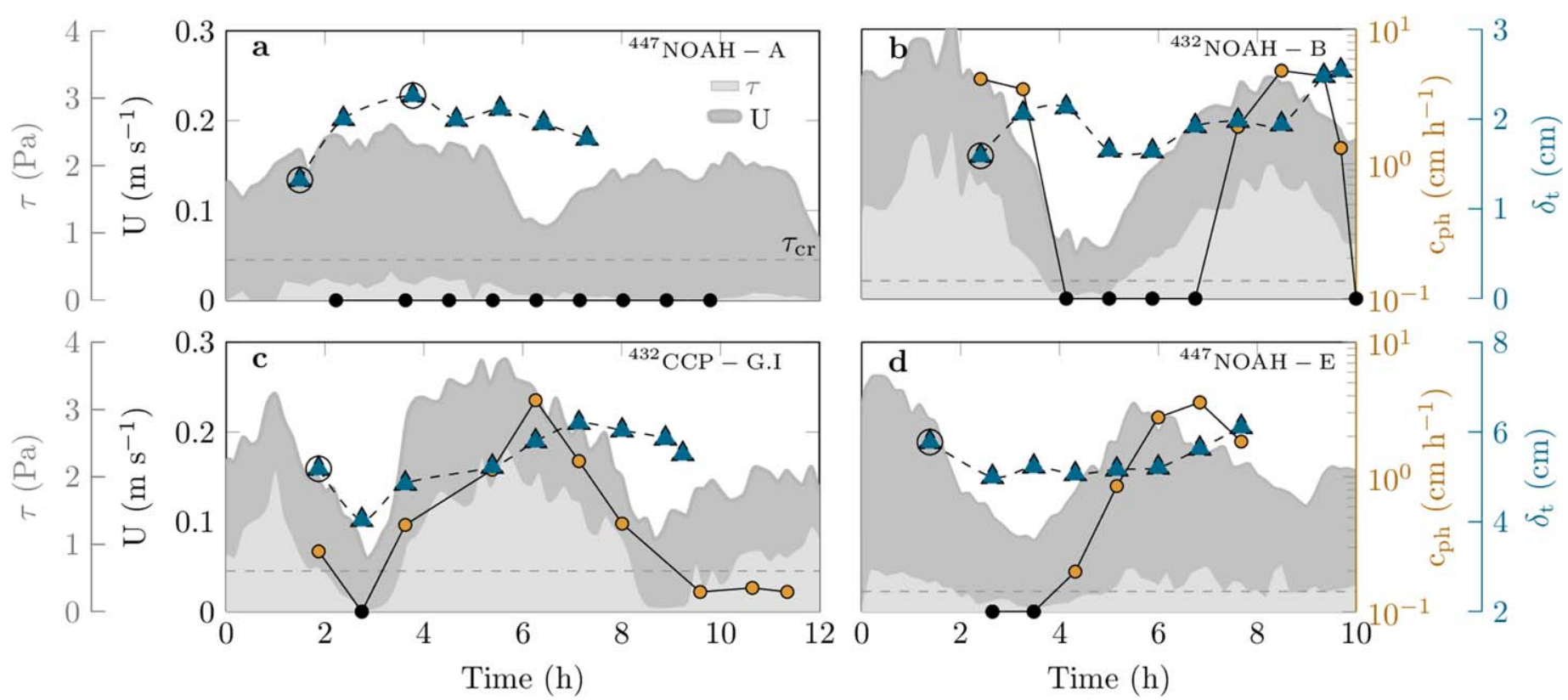

Fig. 2. The transient behavior of the spatially averaged oxygen penetration depth $\left(\delta_{\mathrm{t}} ;\right.$ triangles) and bedform migration ( $c_{\mathrm{ph}}$; filled circles) during a tidal cycle is shown for four representative stations with the bottom water velocity $(U)$ and shear stress $(\tau)$ in the background as dark gray and light gray shaded areas, respectively. The circles around triangles indicate the measurements used for Fig. 5 and Supporting Information Fig. S4. Black circles indicate no detectable bedform migration. The dashed line indicates the critical shear stress at which sediment movement is theoretically initialized. In $\mathbf{d}$ the penetration depth is scaled by a factor of two for visualization purposes.

Sediments that could not be percolated in flow-through reactors were regarded as impermeable to flow (compare Table 3). This was the case for all stations with muddy sand, i.e., ${ }^{432} \mathrm{CCP}-\mathrm{J},{ }^{432} \mathrm{NOAH}-\mathrm{H},{ }^{447} \mathrm{NOAH}-\mathrm{D}$, and ${ }^{447} \mathrm{NOAH}-\mathrm{F}$. Based on the profile measurements, oxygen consumption rates were determined by inversely solving the diffusionreaction equation (Eq. 7). The oxygen consumption rates were averaged down to the oxycline and ranged in between $10 \mu \mathrm{mol} \mathrm{L}^{-1} \mathrm{~h}^{-1}$ and $25 \mu \mathrm{mol} \mathrm{L}^{-1} \mathrm{~h}^{-1}$.

Both, sands and muddy sands were poor in organic carbon with weight percentages ranging from $0.03 \%$ to $0.37 \%$ which is comparable to previous measurements in this region (e.g., de Beer et al. 2005; Janssen et al. 2005; Cook et al. 2007). Organic carbon content did not correlate with oxygen consumption rates indicating that the measured organic carbon content was not a limiting factor.

In Supporting Information Fig. S5 profiles of the particulate organic carbon content are shown for all stations. For migrating bedforms the particulate organic carbon content stayed lowest within the first $2-3 \mathrm{~cm}$ - which was the typical bedform heightand then increases significantly with depth (compare Supporting Information Fig. S6c,d and Fig. S5, significant for all stations with migrating bedforms ( $t$-test: $p<0.05)$ except for stations ${ }^{447} \mathrm{CCP}$ G.I and ${ }^{417} \mathrm{NOAH}-\mathrm{E}(t$-test: $\left.p>0.05)\right)$. For stationary bedforms the trend seems to be similar but with a much larger variability.

\section{Oxygen penetration into the sediment}

The oxygen distribution in the sediments was found highly variable, depending on sediment grain size and permeability, presence and mobility of bedforms, current velocity, and oxygen consumption rate. Oxygen penetration depths were calculated from the distance between the sediment surface and the oxycline, the latter defined as the isoline where oxygen decreased to $5 \%$ of the bottom water concentration. Spatial averages of penetration depths were calculated for each profiling transect and the temporal variation was compared to current regime and sediment transport over a tidal cycle (Fig. 2). Averaged oxygen penetration depth correlated mainly with tidal currents but the amplitude was dampened compared to the current velocity, and delayed by approximately $2 \mathrm{~h}$. The mean oxygen penetration depth for each station was calculated by averaging the spatial averages over a tidal cycle. The values (Table 3) ranged from $0.9 \mathrm{~cm}$ for stations with muddy sand (e.g., $\left.{ }^{432} \mathrm{CCP}-J,{ }^{447} \mathrm{NOAH}-\mathrm{D}\right)$ to $6.4 \mathrm{~cm}$ for stations with coarse grain sizes (e.g., ${ }^{417} \mathrm{CCP}-$ G.I, $\left.{ }^{432} \mathrm{CCP}-\mathrm{G} . \mathrm{I}\right)$. Grain size determines permeability, which controls the advective transport of oxygen into the sediment. Hence, a significant linear relation between grain size and oxygen penetration depth was found (Fig. 4), whereas the effect of oxygen consumption rates on the penetration depths was less obvious and did not result in a significant correlation.

The characteristic porewater velocity $\left(U_{\mathrm{p}}, \mathrm{Eq} .8\right)$, the relative bedform migration $\left(U_{\mathrm{r}}\right.$, Eq. 9), and the Damköhler number $\left(\mathrm{Da}_{\lambda}\right.$, Eq. 10) were calculated for each profile transect and subsequently averaged over a tidal cycle to derive a mean value for each station (Table 3). In Fig. 5, the characteristic variables are used to describe the pattern of oxygen 


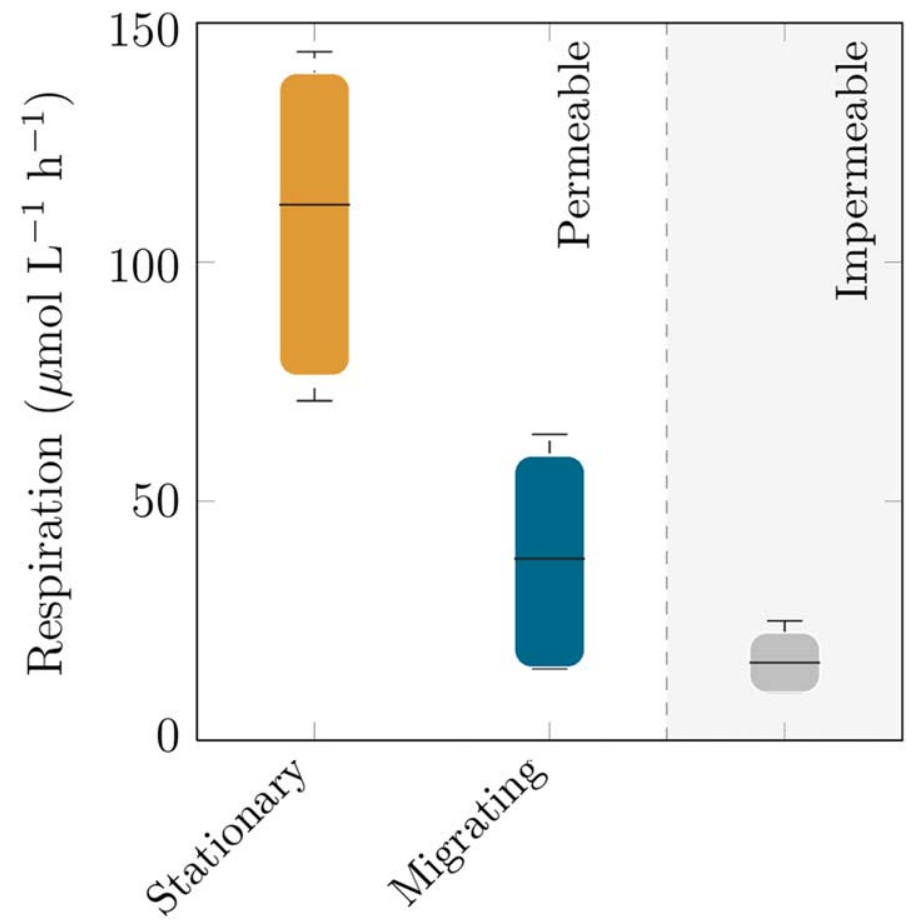

Fig. 3. Boxplots of the volumetric oxygen consumption rates in permeable sediments for stationary and migrating bedforms as well as in impermeable sediments. The upper black line indicates the maximum, the lower black line the minimum, the black line in the box the mean and margins of the colored box represent the $75^{\text {th }}$ percentile and $25^{\text {th }}$ percentile. The means of the two groups differ significantly from each other (ANOVA, $F_{2,13}=19.71, p<0.002$ ).

penetration found at different stations. Four examples are depicted which show typical bedform topographies and associated oxygen distributions. In order to get a better visual impression of the oxygen penetration depth, 12 oxygen profiles per transect were bilinearily interpolated to a 2dimensional distribution. On top, the surface reconstruction was projected with an inclination angle of $30^{\circ}$.

Figure 5a shows a reference example for impermeable muddy sand without considerable seabed topographies. Oxygen in such impermeable sediments follows the flat topography and shows only little lateral variations whereas vertical oxygen gradients are strong. Oxygen penetrated down to $0.9-1.1 \mathrm{~cm}$ (see profiles in Supporting Information Fig. S6a). Similary shallow oxygen penetration depths were observed at all stations composed of impermeable muddy sand (Table 3 ). Even muddy sand stations where bedforms were detected $\left({ }^{447}\right.$ NOAH-D and ${ }^{447}$ NOAH-F, Fig. S4a,b), showed little variations in the oxygen profiles.

Figure $5 \mathrm{~b}$ shows the oxygen distribution underneath a stationary bedform for sandy sediment. The Damköhler number for this sediment is high $\left(\mathrm{Da}_{\lambda}=10\right)$, i.e., the rate of oxygen consumption was high compared to the rate of porewater transport, which agrees with the overall shallow oxygen penetration depth. In between $0.2 \mathrm{~m}$ and $0.5 \mathrm{~m}$ along the $x$-axis

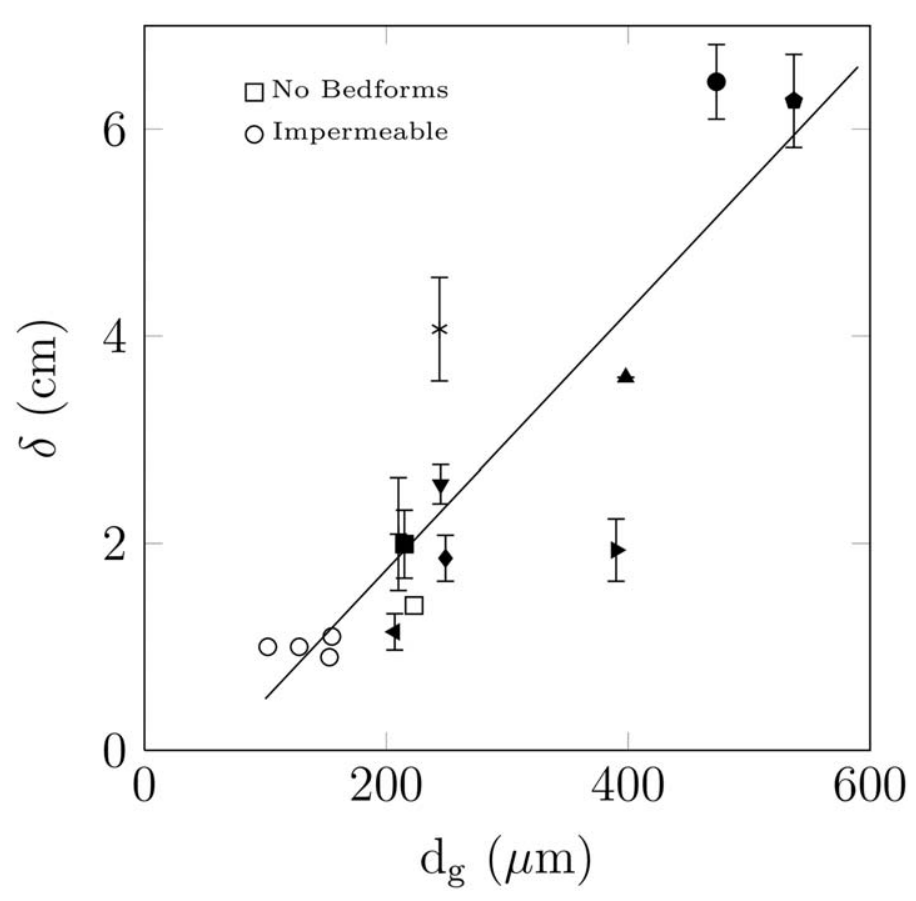

Fig. 4. The average penetration depth $(\delta)$ of oxygen is proportional to the median grain size of permeable sediments $\left(\delta=1.3 \times 10^{-4} d_{\mathrm{g}}-7.5 \times 10^{-3}\right.$, $R^{2}=0.66$ ) indicating the presence of advective porewater flow. Open circles depict penetration depths of stations covered by impermeable sediments. The whiskers denote the standard deviations of the measurements.

two bedforms were detected. The oxygen penetration depth varied in between $1 \mathrm{~cm}$ and $2.5 \mathrm{~cm}$ depending on the position along the bedform. Oxygen penetrated deeper into the bedform at the stoss side compared to the lee side. At the stoss side the oxycline followed the shape of the bedform while it was inclined toward the surface at the lee side. This becomes explicitly visible in the individual oxygen profiles (Supporting Information Fig. S6b). The stoss side profile showed a concave shape with a $2 \mathrm{~cm}$ penetration depth indicating the advective transport. The lee side profile flattens off within $1 \mathrm{~cm}$ showing a convex shape. Similar patterns were visible for all stationary bedforms (Supporting Information Fig. S4c,d).

Figure $5 c$ shows the oxygen distribution underneath a slowly migrating bedform $\left(c_{\mathrm{ph}}=0.2 \mathrm{~cm} \mathrm{~h}^{-1}\right)$. The Damköhler number for this sediment was lower $(\mathrm{Da}=1.7)$, due to the high permeability and the moderate oxygen consumption rates, which results in the deepened oxygen penetration depth (see also Supporting Information Fig. S6c). Bedform migration was slow compared to the characteristic porewater flow $\left(U_{\mathrm{r}}=0.1\right)$, and had no visible effect.

Figure $5 \mathrm{~d}$ shows the oxygen distribution underneath fast migrating bedforms $\left(c_{\mathrm{ph}}=4 \mathrm{~cm} \mathrm{~h}^{-1}\right)$. The bedforms were completely flushed with oxygenated water while exhibiting a strong vertical gradient underneath. In this example, the dominance of another mode of porewater transport becomes apparent. During bedform migration, porewater is released at 

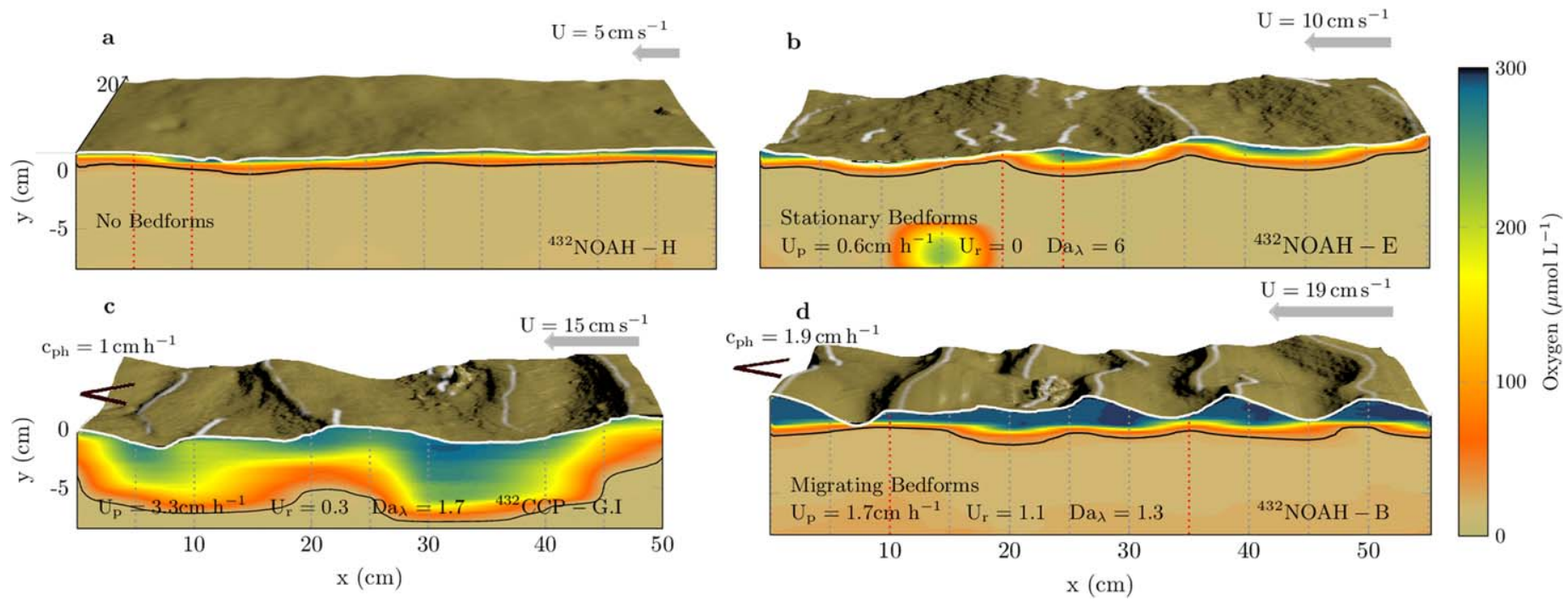

Fig. 5. Examples for surface morphologies and corresponding oxygen distributions are depicted: (a) reference case without bedforms. (b) Stationary bedform where oxygen penetrates from the stoss side into the bedform. (c) Slowly migrating bedform with deep oxygen penetration. (d) Migrating bedforms. The black line indicates the penetration depth were oxygen decreases down to $5 \%$ of the bottom water concentration. The white lines on top of the bedforms are calculated using the edge detecting algorithm and serve as a guide to the eye. The average current strength is indicated by the gray arrow. Notice, induced by the inaccuracies of the Lander's release system, the flow direction is accurate down to $\pm 30^{\circ}$.

the stoss side of the bedform due to erosion of sand grains, while bottom water is trapped at the lee side during redeposition of sand grains. With increasing bedform migration, the bedform becomes fully flushed. The bedform migration was twice as fast $\left(U_{\mathrm{r}}=2\right)$ as the characteristic porewater velocity from pressure driven porewater flow $\left(U_{\mathrm{p}}=2 \mathrm{~cm}\right.$ $\mathrm{h}^{-1}$ ). As found by Ahmerkamp et al. (2015), migrating bedforms lead to variable pressure gradients and porewater flow reversal, which significantly reduces the net porewater flow in the sediment below the bedforms. In this case, the net porewater flow was presumably strongly reduced and the respiration rates were high enough to form a shallow oxycline just below the bedforms (see also Supporting Information Fig. S6d). Nevertheless, despite fast bedform migration, oxygen can penetrate deep if high permeabilities and strong currents drive fast porewater advection. This is the case for station ${ }^{417}$ CCP-G.I (Supporting Information Fig. S4e) where a fast bedform migration of $6.5 \mathrm{~cm} \mathrm{~h}^{-1}$ is not sufficient to override the high characteristic porewater flow $\left(U_{\mathrm{p}}=7.7 \mathrm{~cm}\right.$ $\left.\mathrm{h}^{-1}, U_{\mathrm{r}}=0.9\right)$.

It should be noted that the Damköhler number is only a meaningful variable when the contribution of bedform migration is low, i.e., at low $U_{\mathrm{r}}$, because it relates only the pressure driven porewater flow to the reaction rate. Despite this restriction, a logarithmic function of the mean Damköhler number could explain $60 \%$ of the variation of the mean penetration depths of all permeable stations. This data is not presented here as the explanatory power of the Damköhler number will be investigated in more detail in the Discussion section.

\section{Transient oxygen penetration}

Over the tidal cycle the oxygen penetration depths responded to the changing current velocities and migrating bedforms (Fig. 2). The variation of penetration depths indicates that a certain volume of sediment changed regularly between oxic and anoxic conditions. The thickness of this zone, here referred as variable redox zone, was calculated based on the minimum and maximum deflection of the oxycline along a tidal cycle (Fig. 6). For stationary bedforms the variable redox zone showed a strongly fluctuating thickness depending on the position underneath the bedform (Fig. $6 a)$. For migrating bedforms the thickness of the variable redox zone was spatially constant with smaller variability (Fig. 6b,c).

In Table 3, the relative thickness of the variable redox zone is represented as $\delta_{\mathrm{T}}$, calculated as the ratio of the spatially averaged thickness of the variable redox zone over the thickness of the permanently oxic zone. The variable redox zone was prominent but never exceeded the thickness of the permanently oxic zone $\left(0.2<\delta_{\mathrm{T}}<1\right.$, Table 3$)$. In general, the thickness of the variable redox zone tended to increase with increasing oxygen consumption rates and a significant correlation was found for increasing Damköhler numbers (Fig. 7).

\section{Oxygen flux estimations}

The integration of volumetric oxygen consumption rates over the oxygen penetration depths allows for the estimation of benthic oxygen fluxes. Equation 6 assumes steady state conditions, i.e., the amount of oxygen transported into the sediment is balanced by the oxygen consumption in the sediment. Induced by the transient nature of tides the porewater 

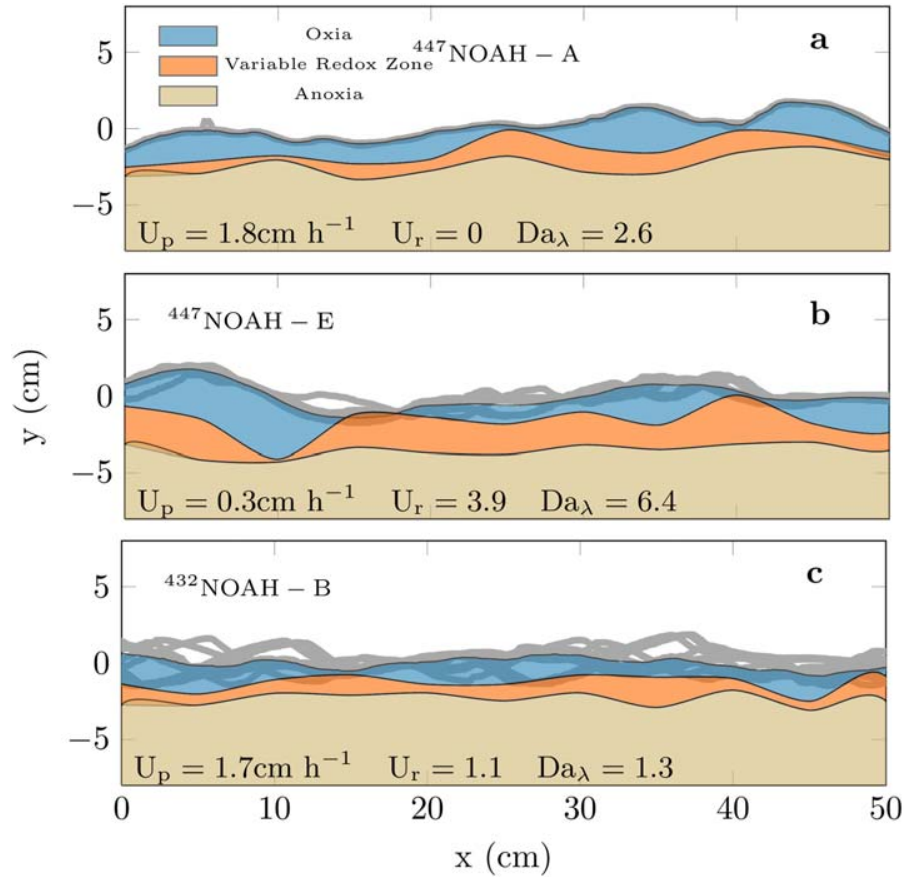

Fig. 6. Transient oxygen penetration depths over a tidal cycle. The orange shaded region encompasses the minimum and maximum deflection of the oxycline and defines the variable redox zone, where both, oxic and anoxic conditions appear over a tidal cycle. The gray line depicts the sediment-water interface for all conducted surface scans. In (a) the bedforms were stationary and the variability of the penetration depth is just induced by the transient currents. In $(\mathbf{b}, \mathbf{c})$ the bedforms were migrating and the variability of oxygen penetration depths is induced by the migrating bedform as well as transient currents. Please note: as the upper end for the oxic region the average surface height was used.

flow varies in strength which induces a response lag of the penetration depth (Fig. 2). Fluxes could be biased when calculated for specific time points and therefore fluxes were estimated using the temporal average of the oxygen penetration depth along a tidal cycle. Oxygen net fluxes varied between $8 \mathrm{mmol} \mathrm{m}^{-2} \mathrm{~d}^{-1}$ and $34 \mathrm{mmol} \mathrm{m}^{-2} \mathrm{~d}^{-1}$ for permeable sediments, whereas, net fluxes at stations with muddy sand varied between $1 \mathrm{mmol} \mathrm{m}^{-2} \mathrm{~d}^{-1}$ and $3 \mathrm{mmol} \mathrm{m}^{-2} \mathrm{~d}^{-1}$ (Table 3 ). For permeable sandy sediments, large oxygen fluxes coincided with large median grain sizes, which corresponds to the increasing penetration depth (Fig. 4). However, the correlation does not explain the full variability since also very high volumetric rates observed at some of the stations led to high oxygen fluxes despite a small grain size $\left({ }^{417} \mathrm{NOAH}-\mathrm{B}, 29\right.$ $\left.\mathrm{mmol} \mathrm{m} \mathrm{m}^{-2} \mathrm{~d}^{-1}, d_{\mathrm{g}}=210 \mu \mathrm{m}\right)$.

When pooling the six stations with bedform migration, it was found that $46 \%$ of the flux variability could be explained by the migration celerity of the bedforms (Supporting Information Fig. S7). High oxygen fluxes coincided with rather low migration celerities and lowest oxygen fluxes were found at highest migration celerities. This correlation

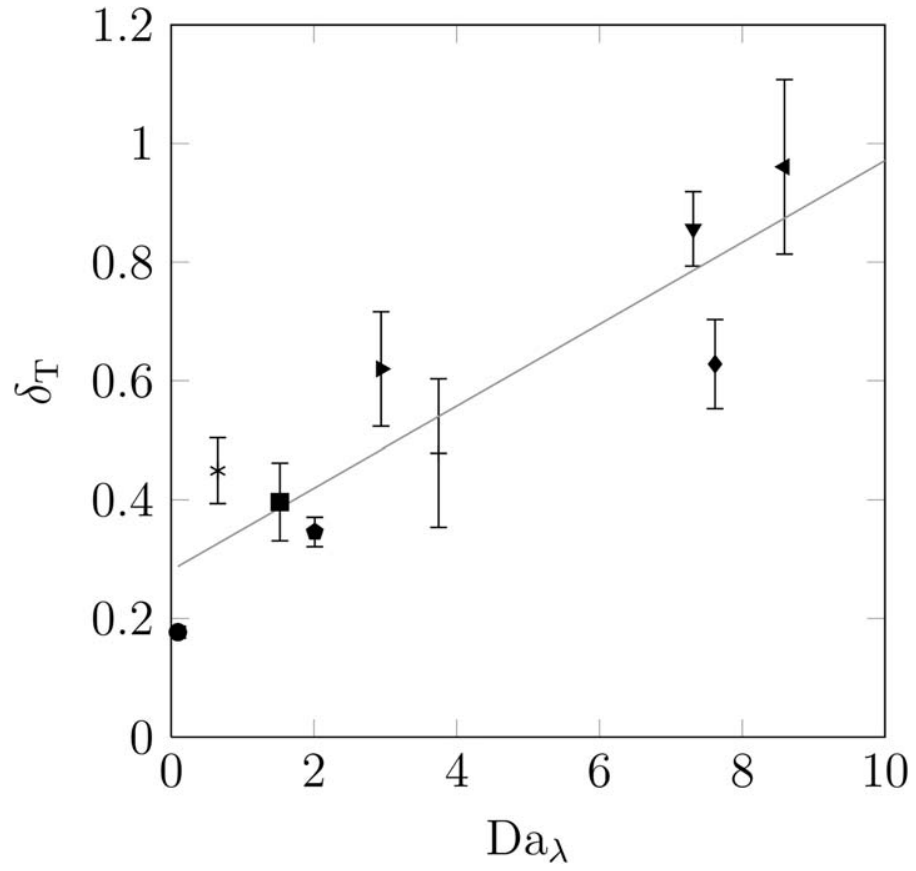

Fig. 7. The relative thickness of the variable redox zone $\left(\delta_{T}\right.$, in $\%$ of the permanently oxic penetration depth $\delta$ ), in which conditions of oxia and anoxia vary along a tidal cycle, scales with the Damköhler number $\left(\delta_{\mathrm{T}}=0.07 \cdot \mathrm{Da}_{\lambda}+0.28, R^{2}=0.8\right)$.

was significantly increased when the net oxygen flux was plotted as a function of the relative migration celerity $U_{\mathrm{r}}$ (Fig. 8). About $81 \%$ of the variability could be explained by using $U_{\mathrm{r}}$ in a power-law. Interestingly, this effect was not exclusively caused by a shallowing oxygen penetration depth as suggested in a recent modeling study (Ahmerkamp et al. 2015). Also the volumetric oxygen consumption rates seemed to decrease with increasing migration celerity (Fig. $8 \mathrm{a}, \mathrm{b})$. This corresponds to the overall decrease of oxygen consumption rates for migrating bedforms (Fig. 3) and can be explained by an enhanced washout of organic particulate matter at higher migration celerity. As a result, it was the interplay of shallowing penetration depths and decreased oxygen consumption rates that caused a significant reduction of the net flux for increasing bedform migration.

When calculating the oxygen flux, the integration of rates include only the oxygen consumption rates measured under bulk oxic conditions in the flow through reactors (FTRs). Thus, the flux calculation does not include the re-oxidation of reduced substance such as $\mathrm{NH}_{4}^{+}, \mathrm{H}_{2} \mathrm{~S}, \mathrm{CH}_{4}, \mathrm{Fe}^{2+}, \mathrm{Mn}^{2+}$ which diffuse upwards from deeper anoxic sediment layers (Glud 2008). Nevertheless, the relative contribution was estimated from porewater profiles of ammonium (Supporting Information Fig. S6d) measured during the field campaign in September 2014 (He 432). For the four sandy stations the vertical gradient below the oxycline was calculated and the upward flux of ammonium was estimated to range between 

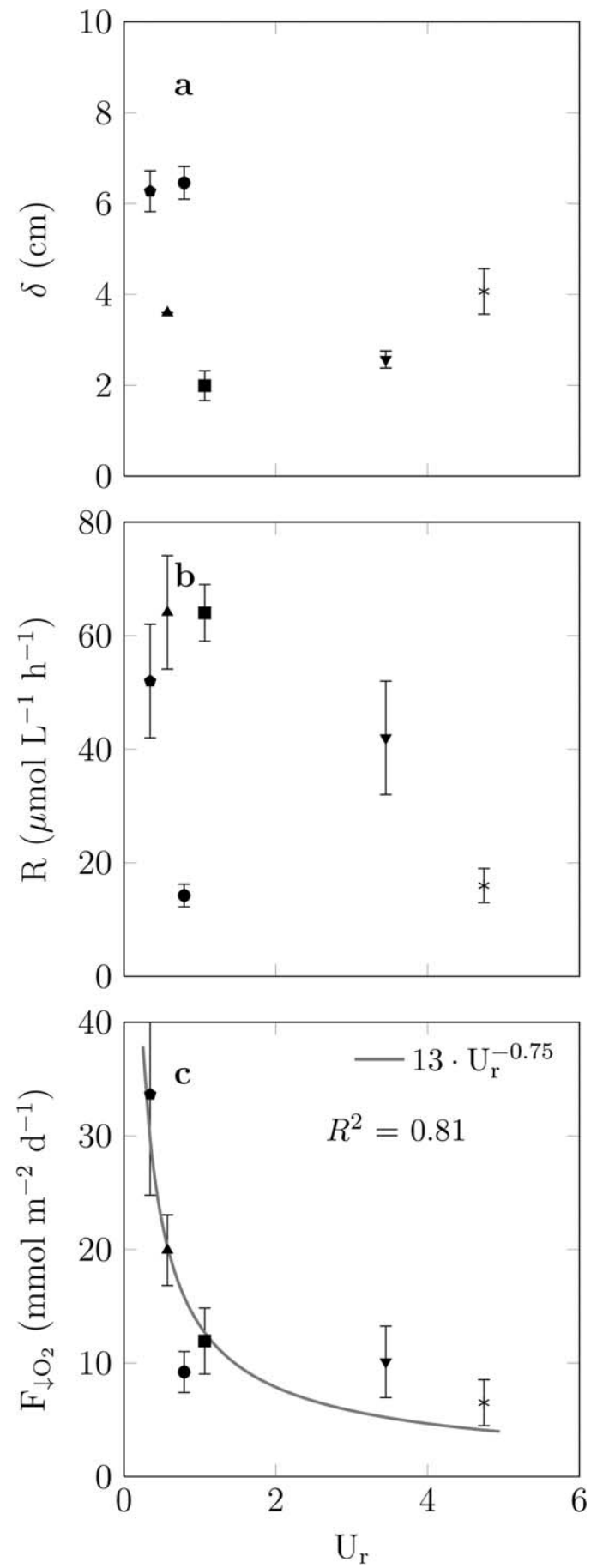

Fig. 8. The impact of bedform migration on the penetration depth (a), volumetric respiration rate (b), and oxygen fluxes (c) along an increasing dominance of bedform migration over porewater velocity as depicted by $U_{r}$.

$0.05 \mathrm{mmol} \mathrm{m} \mathrm{m}^{-2} \mathrm{~d}^{-1}$ and $0.08 \mathrm{mmol} \mathrm{m}^{-2} \mathrm{~d}^{-1}$, assuming a diffusivity of $10^{-9} \mathrm{~m}^{2} \mathrm{~s}^{-1}$. The composition of organic matter in the sediments revealed a relatively constant atomic $\mathrm{C}$ : $\mathrm{N}$ ratio between 5 and 9 which is close to the Redfield ratio of marine biomass $(\mathrm{C}: \mathrm{N}$ is $106: 16=6.6$ or in terms of oxygen $\left.\mathrm{O}_{2}: \mathrm{N} 138: 16=8.6\right)$. The near Redfield stoichiometry of the organic matter in the sediment suggests that the production of ammonium and reduced equivalents also follows the Redfield ratio. Oxidation of both, reduced electron acceptors and ammonium leads to $\mathrm{O}_{2}: \mathrm{N}$ ratios of 7-11. Multiplying the ammonium fluxes with factors of 7-11, results in oxygen fluxes between $0.3 \mathrm{mmol} \mathrm{m}^{-2} \mathrm{~d}^{-1}$ and 0.9 mmol m $\mathrm{m}^{-2} \mathrm{~d}^{-1}$ which is less than $10 \%$ of the measured oxygen flux due to the aerobic respiration.

Bioirrigation patterns (i.e., subsurface maxima) were visible in oxygen profiles from several stations with sandy sediments (examples in Fig. 5b and Supporting Information Fig. S4c,d). However, faunal respiration was excluded from the flux estimates as the oxygen profiling did not allow for its quantification and the volumetric rate measurements did not include the consumption of larger fauna which was removed by sieving (Meysman et al. 2006a; Glud 2008). The calculated fluxes therefore reflect the microbial oxygen uptake and the uptake of all meiofauna that passed the $1 \mathrm{~mm}$ sieve.

\section{Discussion}

We found that small scale bedforms were omnipresent at sandy stations and recorded bedform migration at seven stations depending on the current velocity and the induced shear stress (Fig. 2). The combined effect of sediment permeability, bedform migration, current velocity, and oxygen consumption on the oxygen distribution in the sediment was described for typical settings by means of the dimensionless variables $U_{\mathrm{r}}$ and $\mathrm{Da}_{\lambda}$ (Fig. 5 and Supporting Information Fig. S4). Considering the averaged oxygen penetration depths of all sandy stations, a significant correlation with the median grain size could be established (Fig. 4). At each station, however, the transient forcing of porewater flow and bedform migration caused some variation of the oxygen penetration depths and led to the formation of a layer of variable redox conditions (Fig. 6) that on average represents $60 \%$ of thickness of the permanently oxic zone. The variable redox zone was also well correlated to the Damköhler number (Fig. 7). At stations with bedform migration, oxygen consumption rates in flow-through reactor incubations were lower (Fig. 3), and increased migration velocities correlated with decreasing oxygen fluxes (Fig. 8). In the following we will briefly discuss the limits of the in situ measurements for resolving the transient nature of porewater flow. We will then focus on the estimated oxygen fluxes because they can be best compared to literature values and complementary methods. Thereafter, we discuss the transport-reaction dynamics in sands along specific features and finally present a simple model to predict oxygen penetration depths and subsequently oxygen fluxes.

\section{Temporal resolution of measurements}

The advective porewater transport in permeable sediments is strongly coupled to the hydrodynamic and morphodynamic 
forcing. Fast oxygen and topography measurements were therefore necessary to capture the dynamics in the oxygen distribution along a tidal cycle. A full transect of oxygen profiling took approximately $30 \mathrm{~min}$ which might have led to a misalignment between the topography scans and oxygen measurements in case of fast bedform migration. The upper limit of average bedform migration was $6-7 \mathrm{~cm} \mathrm{~h}^{-1}$ which could lead to a maximum horizontal misalignment between surface and oxygen distribution of $2.5-3 \mathrm{~cm}$. However, this was the case for only two stations $\left({ }^{417} \mathrm{CCP}-\mathrm{GI}\right.$ and $\left.{ }^{417} \mathrm{NOAH}-\mathrm{E}\right)$ where the fast bedform migration coincided with very low rates and, therefore, high penetration depths (see Supporting Information Fig. S4e). In these instances the misalignment has a minor effect on the measured penetration depth as the oxygen distribution showed only little spatial variability in the upper centimeters. In summary, the temporal resolution was sufficient to cover most of the variability along a tidal cycle.

\section{Oxygen fluxes}

We measured oxygen penetration depths between $1 \mathrm{~cm}$ and $6 \mathrm{~cm}$ in sandy sediments with grain sizes ranging from $210 \mu \mathrm{m}$ to $540 \mu \mathrm{m}$. At several stations, the penetration depths correlated with the topography of the bedform and showed a dampened and phase shifted response to tidal currents (Fig. 2). By integrating the measured volumetric oxygen consumption rates down to the averaged oxygen penetration depths, fluxes in permeable sediments could be estimated ranging from $8 \mathrm{mmol} \mathrm{m}^{-2} \mathrm{~d}^{-1}$ to $34 \mathrm{mmol} \mathrm{m}^{-2}$ $\mathrm{d}^{-1}$. The estimated oxygen fluxes represent a conservative range, reflecting mostly physically driven oxygen transport and microbial respiration but neglecting bioirrigation and oxygen uptake by benthic macrofauna. The oxygen fluxes due to re-oxidation of reduced substances that diffuse upwards from deeper layers was less than $10 \%$ of the estimated oxygen flux.

The chosen approach to determine benthic fluxes in permeable sand has the advantage that it is less invasive compared to benthic chamber incubations. In chamber incubations, natural hydrodynamic forcing and sediment transport is excluded, while an arbitrary pressure gradient is imposed by stirring. These limitations were partly addressed by Janssen et al. (2005) who presented chamber incubations in North Sea sediments in which the stirring, and therefore a radial pressure gradient, was adapted to mimic the magnitude of pressure gradients caused by the ambient bottom water velocity. For grain sizes between $163 \mu \mathrm{m}$ and $672 \mu \mathrm{m}$ they measured oxygen fluxes between $8 \mathrm{mmol} \mathrm{m}^{-2} \mathrm{~d}^{-1}$ and $37 \mathrm{mmol} \mathrm{m}^{-2} \mathrm{~d}^{-1}$ which agrees well with the oxygen fluxes measured in this study. Chamber incubations have the advantage that the contribution of macrofauna activity is fully considered, which is not the case in our study. At some stations our profile measurements were complemented by benthic chamber incubations. Oxygen fluxes from two benthic chamber incubations at station ${ }^{447}$ CCP-G.I were found to range in between $15 \mathrm{mmol} \mathrm{m}^{-2} \mathrm{~d}^{-1}$ and $19 \mathrm{mmol} \mathrm{m}^{-2}$ $\mathrm{d}^{-1}$ which is slightly lower than $20 \mathrm{mmol} \mathrm{m}^{-2} \mathrm{~d}^{-1}$ estimated in this study. The offset can be explained by the high sediment permeability, the strong hydrodynamic forcing, and thus the high porewater advection $\left(U_{\mathrm{p}}=2 \mathrm{~cm} \mathrm{~h}^{-1}\right)$ at this station, which is difficult to reproduce within the benthic chambers. At station ${ }^{447} \mathrm{NOAH}-\mathrm{E}$, low sediment permeability, less hydrodynamic forcing, and thus a low porewater advection $\left(U_{\mathrm{p}}=0.3 \mathrm{~cm} \mathrm{~h}^{-1}\right)$ was found, which better met the conditions within the benthic chambers. Oxygen fluxes varied in between $10 \mathrm{mmol} \mathrm{m}^{-2} \mathrm{~d}^{-1}$ and $24 \mathrm{mmol} \mathrm{m}^{-2} \mathrm{~d}^{-1}$ which encompasses the oxygen flux of $13 \mathrm{mmol} \mathrm{m}^{-2} \mathrm{~d}^{-1}$ determined in this study. Here, strong macrofauna respiration may account for the variability. A detailed comaprison of both methods will be published elsewhere (Friedrich et al., unpubl. results).

Another commonly applied approach to measure oxygen fluxes non-invasively is the eddy covariance technique (Berg et al. 2003), which, however, comes with its own set of limitations regarding non-steady state conditions (Holtappels et al. 2013), benthos heterogeneity (Rheuban and Berg 2013), and sensor biases (Holtappels et al. 2015). Eddy covariance fluxes for permeable sediments range from 10 mmol m $\mathrm{m}^{-2} \mathrm{~d}^{-1}$ to $104 \mathrm{mmol} \mathrm{m}^{-2} \mathrm{~d}^{-1}$ for the Mid-Atlantic coast (Hume et al. 2011), 17-19 $\mathrm{mmol} \mathrm{m}^{-2} \mathrm{~d}^{-1}$ for West Falmouth Harbor (Berg et al. 2013), 6-283 $\mathrm{mmol} \mathrm{m}^{-2} \mathrm{~d}^{-1}$ in the northeastern Gulf of Mexico (Berg and Huettel 2008) and $10 \pm 6 \mathrm{mmol} \mathrm{m}^{-2} \mathrm{~d}^{-1}$ in North Sea sediments (McGinnis et al. 2014). In summary, the here presented measurements of oxygen fluxes are average in global comparison but cover the upper range of what was reported for permeable sediments in the North Sea.

\section{Characteristic features of transport-reaction processes in sands}

Besides averaged flux estimations, the measurements collected with the benthic observatory allowed for further insights into the coupled transport-reaction processes in permeable sediments. At all stations with permeable sediments the oxygen distribution followed the small scale topography of bedforms, suggesting that pressure gradients across bedforms were the predominant driver of porewater transport in the surface layers. This agrees with a number of preceding flume studies (e.g., Huettel and Rusch 2000, Huettel et al. 2014; Precht and Huettel 2003) and modelling studies (e.g., Cardenas et al. 2007; Kessler et al. 2012). However, despite large similarities some deviations in comparison to laboratory studies were found. We did not observe the previously described pathway of anoxic porewater from the deep sediment across the sediment-water interface (also known as "anoxic chimneys"), neither for migrating bedforms nor for stationary bedforms. Even at locations where the oxycline was shifted towards the sediment-water interface (e.g., Fig. $6 \mathrm{~b})$, an oxic layer of several $\mathrm{mm}$ thickness indicated that 

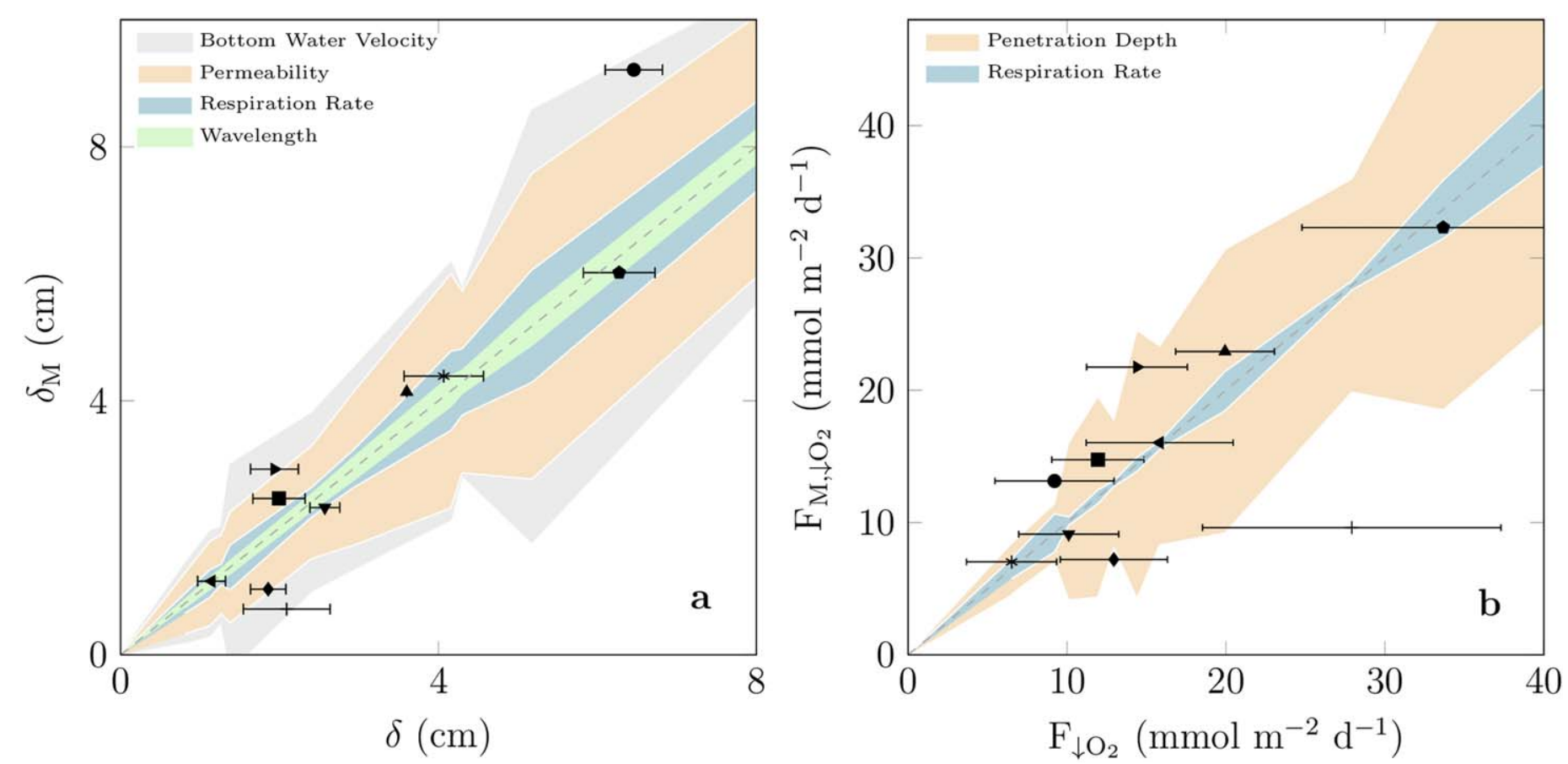

Fig. 9. Comparison of the measured and modeled data (Eqs. 10-11). In (a) the penetration depth and in (b) the oxygen flux is shown (M subscript denotes model). The dashed line indicates the $1: 1$ line. The intervals surrounding the dashed line emphasize the possible uncertainties of the model based on the error of the different input variables. For the penetration depth and bottom water velocity the error is based on the standard deviation of the measurements, for permeability and wavelength $50 \%$ deviation is assumed and for the respiration rate the range between the biological replicates is used. The whiskers denote the standard deviations of the measured penetration depth (a) and fluxes (b).

anoxic porewater does not enter the water column. While aged porewater is still advected upwards and out of the sediments, a considerable fraction of reduced substances, such as ammonium, was most likely oxidized in this oxic layer and was not released into the water column as suggested previously (e.g., Kessler et al. 2013; Huettel et al. 2014).

Studies focusing on stationary bedforms revealed that particulate organic matter accumulates in the sediment leading to the idea of bedforms as biocatalytic filters (Huettel et al. 1996; Huettel and Rusch 2000; Ren and Packman 2004). This picture holds for stationary bedforms, but should be adapted for migrating bedforms as our results indicate a flushing of this filter. The decreased organic carbon content in the upper layer (Supporting Information Fig. S6) and especially the reduced volumetric respiration rate at stations with migrating bedforms (Fig. 3) suggest that particulate organic matter which accumulated in the upper sediment layer is flushed into the water column as soon as the sediment gets perturbated and bedform migration is initialized. Indeed, we found that oxygen fluxes decreased significantly with $U_{\mathrm{r}}^{-0.75}$, i.e., with increasing relative bedform migration (Fig. 8c). Besides the flushing of organic matter and the decrease in volumetric consumption rates, the reduction in oxygen fluxes was also caused by a shallowing of the oxygen penetration depth (Fig. 8a) as described previously in a model study (Ahmerkamp et al. 2015). It was shown that the penetration depth of oxygen decreases as soon as increasing bottom water velocities initialize bedform migration-a counter-intuitive effect given the fact that increasing bottom water velocities should increase the pressure driven advective porewater flow.

The flushing of organic matter is not yet included in most models. However, further evidence for the flushing effect comes from flume experiments where cultures of diatoms, resembling particulate organic matter, were added to the permeable sediment (Pilditch and Miller 2006). In combination with mechanical abrasion of bacteria from sand grains (Nickels et al. 1981) the flushing reduces microbial respiration and thus benthic oxygen fluxes. However, on longer time scales particulate organic matter is redistributed and clogging is suppressed which maintains the system and enhances the benthic-pelagic coupling. The flushing effect will be restricted to organic matter that accumulates near the sediment surface. Non-local mixing of detritus via bioturbation (Meysman et al. 2006b) may still lead to an accumulation of organic matter in deeper sediment layers. Further, some of the particulate organic matter may be transported by means of advection to layers below the characteristic bedform height, which is not affected by flushing via sediment transport.

Important microbial reactions such as denitrification are confined to a specific redox-zone underneath the bedform where the limiting substrate is available and the inhibitory 
effect of oxygen is reduced, at least temporarily. Transient tidal forcing as well as bedform migration constantly changed the extent and position of the oxic zone along a tidal cycle, which led to a constantly oxidized upper layer and a variable oxic-anoxic layer below (Fig. 6) where microorganisms are exposed to variable chemical gradients. The relative extent of this variable redox zone increased with the Damköhler number, which means that large variable redox zones coincide with increased oxygen consumption rates and most likely with increased denitrification rates. It was suggested that the variable redox conditions found in these layers would favor the occurrence of denitrification irrespective of the availability of oxygen as the energetically more favorable electron acceptor (Chen and Strous 2013). Indeed, denitrification under aerobic conditions was frequently observed within permeable sediments (Rao et al. 2007; Gao et al. 2012; Marchant et al. 2016).

\section{Modelling oxygen penetration and oxygen flux}

In correspondence to previous modelling studies (Ahmerkamp et al. 2015; Azizian et al. 2015) we found the oxygen penetration depth to be determined by the relative strength of oxygen consumption rates relative to the oxygen transport rates as summarized by the Damköhler number (Eq. 10, Table 3). When transport rates dominated (low Damköhler number, e.g., $\mathrm{Da}_{\lambda}=0.1$ for ${ }^{417}$ CCP-G.I, Supporting Information Fig. S4e) oxygen was transported deep into the sediment and some oxygen was not consumed but recirculated back into the water column. When oxygen consumption rates dominated (high Damköhler number, e.g., $\mathrm{Da}_{\lambda}=6$ for ${ }^{432}$ NOAH-E, Fig. 5b) the reactive solute was almost completely consumed in the vicinity of the sediment surface.

This behavior is reflected in Eq. 11 which describes the spatially averaged oxygen penetration depth as a function of the inverse Damköhler number and the wavelength of the bedform. Subsequently, oxygen penetration depths were calculated for all sandy stations from the measured input variables as they appear in Eq. 11, i.e., current velocity $U$, bedform length $\lambda$, oxygen concentration $C$, oxygen respiration rate $R$, permeability $k$ (modeled from grain size after Eq. 5 ), and porosity $\theta$. Modeled and measured oxygen penetration depths agree well (Fig. 9a). Despite the fact that the model assumes purely advective porewater flow and stationary bedforms, it performs well on the large range of parameters found in the German Bight during this study. Subsequently, the oxygen net fluxes were modeled by applying Eq. 12. Also the modeled and measured oxygen net fluxes compare well (Fig. 9b). The agreement between measured and modeled results suggest that benthic oxygen fluxes in permeable sediments of the German Bight were to a high degree controlled by advective porewater flow and microbial oxygen consumption rates. Deviations were mainly found at the lower and upper end of penetration depths.
The model uncertainties induced by the error of the measurements were calculated from error propagation and are depicted by the shaded areas in Fig. 9. While the error of bedform length, respiration rate, and bottom water velocity seem to have a minor effect within the observed scales, most of the uncertainty is related to the permeability. Based on the median grain size we used the empirical relation by Gangi et al. (1985) to estimate the permeability. Even though different empirical relations exist, they all have in common that the permeability is a quadratic function of the grain diameter (e.g., Krumbein and Monk 1943; Glover and Walker 2008; Wilson et al. 2008). Therefore, choosing other permeability estimators would not have changed the general pattern but might cause a deviation of the $1: 1$ slope. Considering that also the bedform length and porosity are a function of the grain size the main controlling variables for advective oxygen fluxes in permeable sediments reduce to: grain size, bottom water velocity and volumetric oxygen consumption rate. In contrast to diffusion controlled fluxes, two purely physical variables ( $U$ and $d_{\mathrm{g}}$ ) are among the controlling variables. This might explain the counter intuitive results of Sokoll et al. (2016) who found benthic denitrification fluxes in permeable sediments to correlate better with grain size than with microbial reaction rates. In natural environments, the variability of $U$ and $d_{\mathrm{g}}$ is high and, thus, their effect on benthic fluxes is expected to be more significant compared to the relatively low variability of, e.g., molecular diffusion in cohesive sediments.

\section{Conclusion}

In a series of lander deployments conducted in the shallow North Sea we found average oxygen penetration depths of 1$6 \mathrm{~cm}$ which increase with the sediment grain size and, considering the oxygen consumption rates, can only be explained by advective porewater transport. Oxygen penetration depths responded to changing bottom water velocities with a time lag. In combination with observed bedform migration these transient adaptions created sediment layers in which conditions change frequently between oxia and anoxia. The extent of such variable redox zones was best described by the nondimensional Damköhler number. Further, migrating bedforms led to reduced oxygen fluxes as they caused a shallowing of the penetration depth and a reduction of the oxygen consumption rate in surface sediments, the latter due to the wash out of organic matter during sediment transport. Despite the transient forcing it was found that the varying oxygen penetration depths between the stations are a function of the Damköhler number for which the four main controlling variables are: grain size, current velocity, bottom water oxygen, and oxygen consumption rates. Integrating oxygen consumption rates over the measured oxygen penetration depths resulted in oxygen flux estimates ranging from $8 \mathrm{mmol} \mathrm{m}^{-2} \mathrm{~d}^{-1}$ to $34 \mathrm{mmol} \mathrm{m}^{-2} \mathrm{~d}^{-1}$. 


\section{References}

Ahmerkamp, S., C. Winter, F. Janssen, M. M. M. Kuypers, and M. Holtappels. 2015. The impact of bedform migration on benthic oxygen fluxes. J. Geophys. Res. 120: 2229-2242. doi:10.1002/2015JG003106

Ayoub, F., J.-P. Avouac, C. E. Newman, M. I. Richardson, A. Lucas, S. Leprince, and N. T. Bridges. 2014. Threshold for sand mobility on mars calibrated from seasonal variations of sand flux. Nat. Commun. 5: 1-9. doi:10.1038/ncomms6096

Azizian, M., S. B. Grant, A. J. Kessler, P. L. M. Cook, M. A. Rippy, and M. Stewardson. 2015. Bedforms as biocatalytic filters: A pumping and streamline segregation (pass) model for nitrate removal in permeable sediments. Environ. Sci. Technol. 49: 10993-11002. doi:10.1021/acs.est.5b01941

Berg, P., N. Risgaard-Petersen, and S. Rysgaard. 1998. Interpretation of measured concentration profiles in sediment pore water. Limnol. Oceanogr. 43: 1500-1510. doi: 10.4319/1o.1998.43.7.1500

Berg, P., H. Röy, F. Janssen, V. Meyer, B. B. Jörgensen, M. Huettel, and D. De Beer. 2003. Oxygen uptake by aquatic sediments measured with a novel non-invasive eddy-correlation technique. Mar. Ecol. Prog. Ser. 261: 75-83. doi: 10.3354/meps261075

Berg, P., and M. Huettel. 2008. Monitoring the seafloor using the noninvasive eddy correlation technique: Integrated benthic exchange dynamics. Oceanography 21: 164. doi: 10.5670/oceanog.2008.13

Berg, P., and others. 2013. Eddy correlation measurements of oxygen fluxes in permeable sediments exposed to varying current flow and light. Limnol. Oceanogr. 58: 1329-1343. doi:10.4319/lo.2013.58.4.1329

Boudreau, B. P., and others. 2001. Permeable marine sediments: Overturning an old paradigm. EOS Trans. Am. Geophys. Union 82: 133-136. doi:10.1029/EO082i011p00133-01

Brockmann, U., G. Billen, and W. W. C. Gieskes. 1988. North sea nutrients and eutrophication, p. 348-389. In W. Salomons et al. (Ed.), Pollution of the north sea. Springer. doi: 10.1007/978-3-642-73709-1_20

Cardenas, M. B., and J. L. Wilson. 2007. Dunes, turbulent eddies, and interfacial exchange with permeable sediments. Water Resour. Res. 43. doi:10.1029/2006WR005787

Chen, J., and M. Strous. 2013. Denitrification and aerobic respiration, hybrid electron transport chains and co-evolution. Biochim. Biophys. Acta 1827: 136-144. doi: 10.1016/j.bbabio.2012.10.002

Chiswell, S. M. 2011. Annual cycles and spring blooms in phytoplankton: Don't abandon sverdrup completely. Mar. Ecol. Prog. Ser. 443: 39-50. doi:10.3354/meps09453

Coelingh, J. P., J. M. Van Wijk, and A. A. M. Holtslag. 1996. Analysis of wind speed observations over the North Sea. J. Wind Eng. Ind. Aerodyn. 61: 51-69. doi:10.1016/S0167-6105(97)00285-7

Cook, P. L. M., F. Wenzhöfer, R. N. Glud, F. Janssen, and M. Huettel. 2007. Benthic solute exchange and carbon mineralization in two shallow subtidal sandy sediments: Effect of advective pore-water exchange. Limnol. Oceanogr. 52: 1943-1963. doi:10.4319/lo.2007.52.5.1943

de Beer, D., and others. 2005. Transport and mineralization rates in north sea sandy intertidal sediments, sylt-rømø basin, wadden sea. Limnol. Oceanogr. 50: 113-127. doi: 10.4319/lo.2005.50.1.0113

DeFlaun, M. F., and L. M. Mayer. 1983. Relationships between bacteria and grain surfaces in intertidal sediments. Limnol. Oceanogr. 28: 873-881. doi:10.4319/lo.1983.28.5.0873

Dey, S. 2014. Fluvial processes: Hydrodynamic and sediment transport phenomena. Springer.

Elliott, A. H., and N. H. Brooks. 1997. Transfer of nonsorbing solutes to a streambed with bed forms: Theory. Water Resour. Res. 33: 123-136. doi:10.1029/96WR02784

Emery, K. O. 1968. Relict sediments on continental shelves of world. AAPG Bull. 52: 445-464.

Folk, R. L. 1980. Petrology of sedimentary rocks. Hemphill Publishing Company.

Gao, H., and others. 2012. Intensive and extensive nitrogen loss from intertidal permeable sediments of the wadden sea. Limnol. Oceanogr. 57: 185. doi:10.4319/lo.2012.57.1.0185

Gangi, A. F. 1978. Variation of whole and fractured porous rock permeability with confining pressure. International Journal of Rock Mechanics and Mining Sciences \& Geomechanics Abstracts. Vol. 15. No. 5. Pergamon. doi:10.1016/ 0148-9062(78)90957-9

Gerlach, S. A. 1981. Marine pollution. Springer-Verlage Berlin Heidelberg. doi:10.1007/978-3-642-68182-0

Glover, P. W., and E. Walker. 2008. Grain-size to effective pore-size transformation derived from electrokinetic theory. Geophysics 74: E17-E29. doi:10.1190/1.3033217

Glud, R. N., and others. 2003. Seasonal dynamics of benthic $\mathrm{O} 2$ uptake in a semienclosed bay: Importance of diffusion and faunal activity. Limnology and Oceanography 48.3: 1265-1276. doi:10.4319/lo.2003.48.3.1265

Glud, R. N. 2008. Oxygen dynamics of marine sediments. Mar. Biol. Res. 4: 243-289. doi:10.1080/17451000801888726

Grashorn, S., K. A. Lettmann, J. Wolff, T. H. Badewien, and E. V. Stanev. 2015. East frisian wadden sea hydrodynamics and wave effects in an unstructured-grid model. Ocean Dyn. 65: 419-434. doi:10.1007/s10236-014-0807-5

Hickel, W., P. Mangelsdorf, and J. Berg. 1993. The human impact in the german bight: Eutrophication during three decades (1962-1991). Helgoländer Meeresuntersuchungen 47: 243-263. doi:10.1007/BF02367167

Holtappels, M., R. N. Glud, D. Donis, B. Liu, A. Hume, F. Wenzhöfer, and M. M. M. Kuypers. 2013. Effects of transient bottom water currents and oxygen concentrations on benthic exchange rates as assessed by eddy correlation measurements. J. Geophys. Res. 118: 1157-1169. doi: 10.1002/jgrc.20112

Holtappels, M., C. Noss, K. Hancke, C. Cathalot, D. F. McGinnis, A. Lorke, and R. N. Glud. 2015. Aquatic eddy 
correlation: Quantifying the artificial flux caused by stirring-sensitive O2 sensors. PloS One 10: e0116564. doi: 10.1371/journal.pone.0116564

Huettel, M., W. Ziebis, and S. Forster. 1996. Flow-induced uptake of particulate matter in permeable sediments. Limnol. Oceanogr. 41: 309-322. doi:10.4319/lo.1996.41.2.0309

Huettel, M., and A. Rusch. 2000. Transport and degradation of phytoplankton in permeable sediment. Limnol. Oceanogr. 45: 534-549. doi:10.4319/lo.2000.45.3.0534

Huettel, M., P. Berg, and J. E. Kostka. 2014. Benthic exchange and biogeochemical cycling in permeable sediments. Mar. Sci. 6: 23-51. doi:10.1146/annurev-marine-051413-012706

Hume, A. C., P. Berg, and K. J. McGlathery. 2011. Dissolved oxygen fluxes and ecosystem metabolism in an eelgrass (zostera marina) meadow measured with the eddy correlation technique. Limnol. Oceanogr. 56: 86. doi:10.4319/ lo.2011.56.1.0086

Jahnke, R. A. 2010. Global synthesis, p. 597-615. In Prof. K. Liu, Prof. L. Atkinson, Prof. R. Quipones, \& Dr. L. TalaueMcManu (Eds.), Carbon and nutrient fluxes in continental margins. Springer. ISBN: 978-3-540-92734-1

Janssen, F., M. Huettel, and U. Witte. 2005. Pore-water advection and solute fluxes in permeable marine sediments (ii): Benthic respiration at three sandy sites with different permeabilities (german bight, north sea). Limnol. Oceanogr. 50: 779-792. doi:10.4319/lo.2005.50.3.0779

Janssen, F., M. B. Cardenas, A. H. Sawyer, T. Dammrich, J. Krietsch, and D. de Beer. 2012. A comparative experimental and multiphysics computational fluid dynamics study of coupled surfac-subsurface flow in bed forms. Water Resour. Res. 48. doi:10.1029/2012WR011982

Kérouel, R., and A. Aminot. 1997. Fluorometric determination of ammonia in sea and estuarine waters by direct segmented flow analysis. Mar. Chem. 57: 265-275. doi: 10.1016/S0304-4203(97)00040-6

Kessler, A. J., N. Glud, M. B. Cardenas, M. Larsen, M. F. Bourke, and P. L. Cook. 2012. Quantifying denitrification in rippled permeable sands through combined flume experiments and modeling. Limnol. Oceanogr. 57: 12171232. doi:10.4319/lo.2012.57.4.1217

Kessler, A. J., N. Glud, M. B. Cardenas, and P. L. Cook. 2013. Transport zonation limits coupled nitrificationdenitrification in permeable sediments. Environ. Sci. Technol. 47: 13404-13411. doi:10.1021/es403318x

Krämer, K., and C. Winter. 2016. Predicted ripple dimensions in relation to the precision of in situ measurements in the southern North Sea. Ocean Sci. 12: 1221-1235. doi: 10.5194/os-12-1221-2016

Krumbein, W. C., and G. D. Monk. 1943. Permeability as a function of the size parameters of unconsolidated sand. Trans. AIME 151: 153-163. doi:10.2118/943153-G

Lettmann, K. A., N. Riedinger, R. Ramlau, N. Knab, M. E. Böttcher, A. Khalili, J. Wolff, and B. B. Jørgensen. 2012. Estimation of biogeochemical rates from concentration profiles: A novel inverse method. Estuar. Coast. Shelf Sci. 100: 26-37. doi:10.1016/j.ecss.2011.01.012

Marchant, H. K., G. Lavik, M. Holtappels, and M. M. M. Kuypers. 2014. The fate of nitrate in intertidal permeable sediments. PloS One 9: e104517. doi:10.1371/journal.pone.0104517

Marchant, H. K., M. Holtappels, G. Lavik, S. Ahmerkamp, C. Winter, and M. M. M. Kuypers. 2016. Coupled nitrificationdenitrification leads to extensive $\mathrm{n}$ loss in subtidal permeable sediments. Limnol. Oceanogr. 61: 1033-1048. doi: 10.1002/lno.10271

McGinnis, D. F., S. Sommer, A. Lorke, R. N. Glud, and P. Linke. 2014. Quantifying tidally driven benthic oxygen exchange across permeable sediments: An aquatic eddy correlation study. J. Geophys. Res. 119: 6918-6932. doi: 10.1002/2014JC010303

Meysman, F. J. R., S. Galaktionov, B. Gribsholt, and J. J. Middelburg. 2006a. Bioirrigation in permeable sediments: Advective pore-water transport induced by burrow ventilation. Limnol. Oceanogr. 51: 142-156. doi:10.4319/ lo.2006.51.1.0142

Meysman, F. J. R., J. Middelburg, and C. H. R. Heip. $2006 b$. Bioturbation: A fresh look at Darwin's last idea. Trends Ecol. Evol. 21: 688-695. doi:10.1016/j.tree.2006.08.002

Nickels, J. S., J. Bobbie, R. F. Martz, G. A. Smith, D. C. White, and N. L. Richards. 1981. Effect of silicate grain shape, structure, and location on the biomass and community structure of colonizing marine microbiota. Appl. Environ. Microbiol. 41: 1262-1268.

Otto, L., J. T. F. Zimmerman, G. K. Furnes, M. Mork, R. Saetre, and G. Becker. 1990. Review of the physical oceanography of the North Sea. Neth. J. Sea Res. 26: 161-238. doi:10.1016/0077-7579(90)90091-T

Pilditch, C. A., and D. C. Miller. 2006. Phytoplankton deposition to permeable sediments under oscillatory flow: Effects of ripple geometry and resuspension. Cont. Shelf Res. 26: 1806-1825. doi:10.1016/j.csr.2006.06.002

Precht, E., and M. Huettel. 2003. Advective pore-water exchange driven by surface gravity waves and its ecological implications. Limnol. Oceanogr. 48: 1674-1684. doi: 10.4319/1o.2003.48.4.1674

Precht, E., U. Franke, L. Polerecky, and M. Huettel. 2004. Oxygen dynamics in permeable sediments with wavedriven pore water exchange. Limnol. Oceanogr. 49: 693705. doi:10.4319/lo.2004.49.3.0693

Probandt, D., K. Knittel, H. E. Tegetmeyer, S. Ahmerkamp, M. Holtappels, and R. Amann. 2017. Permeability shapes bacterial communities in sublittoral surface sediments. Environ. Microbiol. doi:10.1111/1462-2920.13676

Rabalais, N. N., E. Turner, Q. Dortch, D. Justic, V. J. Bierman, Jr., and W. J. Wiseman, Jr. 2002. Nutrients and Eutrophication in Estuaries and Coastal Waters. E. Orive, M. Elliott, \& V.N. de Jonge (Eds.), Series Developments in Hydrobiology, 164: 39-63, Springer Verlag. doi:10.1023/A: 1020388503274 
Rao, A. M. F., J. McCarthy, W. S. Gardner, and R. A. Jahnke. 2007. Respiration and denitrification in permeable continental shelf deposits on the south atlantic bight: Rates of carbon and nitrogen cycling from sediment column experiments. Cont. Shelf Res. 27: 1801-1819. doi: 10.1016/j.csr.2007.03.001

Raudkivi, A. J. 1997. Ripples on stream bed. J. Hydraul. Eng. 123: 58-64. doi:10.1061/(ASCE)0733-9429(1997)123:1(58)

Reimers, C. E., A. Stecher, III, G. L. Taghon, C. M. Fuller, M. Huettel, A. Rusch, N. Ryckelynck, and C. Wild. 2004. In situ measurements of advective solute transport in permeable shelf sands. Cont. Shelf Res. 24: 183-201. doi: 10.1016/j.csr.2003.10.005

Ren, J., and A. I. Packman. 2004. Modeling of simultaneous exchange of colloids and sorbing contaminants between streams and streambeds. Environ. Sci. Technol. 38: 29012911. doi:10.1021/es0348521

Rheuban, J. E., and P. Berg. 2013. The effects of spatial and temporal variability at the sediment surface on aquatic eddy correlation flux measurements. Limnol. Oceanogr.: Methods 11: 351-359. doi:10.4319/lom.2013.11.351

Rusch, A., M. Huettel, C. E. Reimers, G. L. Taghon, and C. M. Fuller. 2003. Activity and distribution of bacterial populations in middle atlantic bight shelf sands. FEMS Microbiol. Ecol. 44: 89-100. doi:10.1111/j.1574-6941. 2003.tb01093.x

Rutherford, J. C., J. Latimer, and R. K. Smith. 1993. Bedform mobility and benthic oxygen uptake. Water Res. 27: 1545-1558. doi:10.1016/0043-1354(93)90099-4

Santos, I. R., D. Eyre, and M. Huettel. 2012a. The driving forces of porewater and groundwater flow in permeable coastal sediments: A review. Estuar. Coast. Shelf Sci. 98: 1-15. doi:10.1016/j.ecss.2011.10.024

Santos, I. R., D. Eyre, and R. N. Glud. 2012b. Influence of porewater advection on denitrification in carbonate sands: Evidence from repacked sediment column experiments. Geochim. Cosmochim. Acta 96: 247-258. doi: 10.1016/j.gca.2012.08.018

Seeberg-Elverfeldt, J., M. Schlüter, T. Feseker, and M. Kölling. 2005. Rhizon sampling of porewaters near the sedimentwater interface of aquatic systems. Limnol. Oceanogr.: Methods 3: 361-371. doi:10.4319/lom.2005.3.361

Simon, M., H. Grossart, B. Schweitzer, and H. Ploug. 2002. Microbial ecology of organic aggregates in aquatic ecosystems. Aquat. Microb. Ecol. 28: 175-211. doi:10.3354/ame028175

Sokoll, S., Lavik, G., Sommer, S., Goldhammer, T., Kuypers, M. M., Holtappels, M. 2016. Extensive nitrogen loss from permeable sediments off North-West Africa. Journal of Geophysical Research: Biogeosciences. 121: 1144-1157. doi:10.1002/2015JG003298

Soulsby, R. 1997. Dynamics of marine sands: a manual for practical applications. Thomas Telford. ISBN-13: 978-0727725844

Stonedahl, S. H., W. Harvey, A. Wörman, M. Salehin, and A. I. Packman. 2010. A multiscale model for integrating hyporheic exchange from ripples to meanders. Water Resour. Res. 46: 1-14. doi:10.1029/2009WR008865
Sverdrup, H. U., W. Johnson, and R. H. Fleming. 1942. The oceans: Their physics, chemistry, and general biology, $\mathrm{v}$. 7. Prentice-Hall.

Traykovski, P. 2007. Observations of wave orbital scale ripples and a nonequilibrium time-dependent model. Journal of Geophysical Research: Oceans 112.C6. doi:10.1029/ 2006JC003811

Thibodeaux, L. J., and J. D. Boyle. 1987. Bedform-generated convective transport in bottom sediment. Nature 325: 341-343. doi:10.1038/325341a0

Thomas, H., Y. Bozec, K. Elkalay, and H. J. W. De Baar. 2004. Enhanced open ocean storage of $\mathrm{CO} 2$ from shelf sea pumping. Science 304: 1005-1008. doi:10.1126/science.1095491

van Beusekom, J. E. E. 2005. A historic perspective on wadden sea eutrophication. Helgol. Mar. Res. 59: 45-54. doi: 10.1007/s10152-004-0206-2

Van Duyl, F. C., and A. J. Kop. 1994. Bacterial production in north sea sediments: Clues to seasonal and spatial variations. Mar. Biol. 120: 323-337. doi:10.1007/BF00349694

Wang, G., A. J. Spivack, S. Rutherford, U. Manor, and S. D'Hondt. 2008. Quantification of co-occurring reaction rates in deep subseafloor sediments. Geochim. Cosmochim. Acta 72: 3479-3488. doi:10.1016/j.gca.2008.04.024

Wiberg, P. L., and C. R. Sherwood. 2008. Calculating wavegenerated bottom orbital velocities from surface-wave parameters. Comput. Geosci. 34: 1243-1262. doi:10.1016/ j.cageo.2008.02.010

Wilson, A. M., M. Huettel, and S. Klein. 2008. Grain size and depositional environment as predictors of permeability in coastal marine sands. Estuar. Coast. Shelf Sci. 80: 193199. doi:10.1016/j.ecss.2008.06.011

Ziebis, W., M. Huettel, and S. Forster. 1996. Impact of biogenic sediment topography on oxygen fluxes in permeable seabeds. Mar. Ecol. Prog. Ser. 140: 227-237. doi:10.3354/meps140227

\section{Acknowledgments}

We are grateful for help during the technical development of the benthic observatory by Paul Faerber, Volker Meyer and Georg Herz. We are thankful to the captain and crew members of the R/V Heincke (He417, He432, He447) for their outstanding collaboration and support during the survey. We thank Tomas Wilkop for his logistic support. We sincerely thank Gabi Klockgether and Kirsten Imhoff for technical assistance, and Julia Amelsberg for help with measurements. We also thank Hannah Marchant, Andreas Neumann, and three anonymous reviewers for valuable discussions and comments that helped improving the manuscript. The study was funded by the Max Planck Society and the DFG-Research Center/Cluster of Excellence "The Ocean in the Earth System" at the University of Bremen.

\section{Conflict of Interest}

None declared.
Submitted 22 June 2016

Revised 14 January 2017 Accepted 14 February 2017 Associate editor: Ronnie Glud 